\title{
PAPERS FROM ACTUARIAL JOURNALS WORLDWIDE
}

Single copies of the papers listed here can be obtained, subject to charge and copyright regulations, from the libraries of the Institute and Faculty of Actuaries. Members can also access the journals online by registering for the libraries’ Athens service. Email: libraries@ actuaries.org.uk or telephone 01312401311 or 02076322114 for a password.

\section{ASTIN Bulletin}

$$
\text { 44(3), } 2014
$$

BERNARD, CAROLE; HARDY, MARY; MACKAY, ANNE. State-dependent fees for variable annuity guarantees. 559-585. For variable annuity policies, management fees for the most basic guarantees are charged at a constant rate throughout the term of the policy. This creates a misalignment of risk and income - the fee income is low when the option value is high, and vice versa. In turn, this may create adverse incentives for policyholders, for example, encouraging surrenders when the options are far out-of-the-money. In this paper, we explore a new fee structure for variable annuities, where the fee rate supporting the cost of guarantees depends on the moneyness of those guarantees. We derive formulas for calculating the fee rates assuming fees are paid only when the guarantees are in-the-money, or are close to being in-the-money, and we illustrate with some numerical examples. We investigate the effect of this new fee structure on the surrender decision.

BOUCHER, JEAN-PHILIPPE; INOUSSA, ROFICK. A Posteriori ratemaking with panel data. 587-612. Ratemaking is one of the most important tasks of non-life actuaries. Usually, the ratemaking process is done in two steps. In the first step, a priori ratemaking, an a priori premium is computed based on the characteristics of the insureds. In the second step, called the a posteriori ratemaking, the past claims experience of each insured is considered to the a priori premium and set the final net premium. In practice, for automobile insurance, this correction is usually done with bonus-malus systems, or variations on them, which offer many advantages. In recent years, insurers have accumulated longitudinal information on their policyholders, and actuaries can now use many years of informations for a single insured. For this kind of data, called panel or longitudinal data, we propose an alternative to the two-step ratemaking approach and argue this old approach should no longer be used. As opposed to a posteriori models of cross-section data, the models proposed in this paper generate premiums based on empirical results rather than inductive probability. We propose a new way to deal with bonus-malus systems when panel data are available. Using car insurance data, a numerical illustration using at-fault and non-at-fault claims of a Canadian insurance company is included to support this discussion. Even if we apply the model for car insurance, as long as another line of business uses past claim experience to set the premiums, we maintain that a similar approach to the model proposed should be used.

CHRISTIANSEN, MARCUS C; NIEMEYER, ANDREAS. Fundamental definition of the solvency capital requirement in solvency II. 501-533. It is essential for insurance regulation to have a clear 
picture of the risk measures that are used. We compare different mathematical interpretations of the Solvency Capital Requirement (SCR) definition from Solvency II that can be found in the literature. We introduce a mathematical modeling framework that enables us to make a mathematically rigorous comparison. The paper shows similarities, differences, and properties such as convergence of the different SCR interpretations. Moreover, we generalize the SCR definition to future points in time based on a generalization of the value at risk. This allows for a sound definition of the Risk Margin. Our study helps to make the Solvency II insurance regulation more consistent.

DAL MORO, ERIC; LO, JOSEPH. An industry question: the ultimate and one-year reserving uncertainty for different non-life reserving methodologies. 495-499. In the industry, generally, reserving actuaries use a mix of reserving methods to derive their best estimates. On the basis of the best estimate, Solvency 2 requires the use of a one-year volatility of the reserves. When internal models are used, such one-year volatility has to be provided by the reserving actuaries. Due to the lack of closed-form formulas for the one-year volatility of Bornhuetter-Ferguson, Cape-Cod and Benktander-Hovinen, reserving actuaries have limited possibilities to estimate such volatility apart from scaling from tractable models, which are based on other reserving methods. However, such scaling is technically difficult to justify cleanly and awkward to interact with. The challenge described in this editorial is therefore to come up with similar models like those of Mack or Merz-Wüthrich for the chain ladder, but applicable to Bornhuetter-Ferguson, mix Chain-Ladder and Bornhuetter-Ferguson, potentially Cape-Cod and Benktander-Hovinen - and their mixtures.

FENG, RUNHUAN; VOLKMER, HANS W. Spectral methods for the calculation of risk measures for variable annuity guaranteed benefits. 653-681. Spectral expansion techniques have been extensively exploited for the pricing of exotic options. In this paper, we present novel applications of spectral methods for the quantitative risk management of variable annuity guaranteed benefits such as guaranteed minimum maturity benefits and guaranteed minimum death benefits. The objective is to find efficient and accurate solution methods for the computation of risk measures, which is the key to determining risk-based capital according to regulatory requirements. Our example calculations show that two spectral methods used in this paper are highly efficient and numerically more stable than conventional known methods. Hence these approaches are more suitable for intensive calculations involving death benefits.

HÜRLIMANN, WERNER. On some properties of two vector-valued VaR and CTE multivariate risk measures for Archimedean copulas. 613-633. We consider the multivariate Value-at-Risk (VaR) and Conditional-Tail-Expectation (CTE) risk measures introduced in Cousin and Di Bernardino (Cousin, A. and Di Bernardino, E. (2013) Journal of Multivariate Analysis, 119, 32-46; Cousin, A. and Di Bernardino, E. (2014) Insurance: Mathematics and Economics, 55(C), 272-282). For absolutely continuous Archimedean copulas, we derive integral formulas for the multivariate VaR and CTE Archimedean risk measures. We show that each component of the multivariate VaR and CTE functional vectors is an integral transform of the corresponding univariate $\mathrm{VaR}$ measures. For the class of Archimedean copulas, the marginal components of the CTE vector satisfy the following properties: positive homogeneity $(\mathrm{PH})$, translation invariance (TI), monotonicity (MO), safety loading (SL) and VaR inequality (VIA). In case marginal risks satisfy the subadditivity (MSA) property, the marginal CTE components are also sub-additive and hitherto coherent risk measures in the usual sense. Moreover, the increasing risk (IR) or stop-loss order preserving property of the marginal CTE components holds for the class of bivariate Archimedean copulas. A counterexample to the (IR) property for the trivariate Clayton copula is included. 
KLING, ALEXANDER; RICHTER, ANDREAS; RUß, JOCHEN. Annuitization behavior: tax incentives vs. product design. 535-558. We analyze and compare the impact of tax incentives and of introducing enhanced annuities on annuitization behavior considering heterogeneity among the insured. We find that tax incentives for annuitization result in a significant increase of the portion of people who should annuitize and also an increase of the insurer's profit since less healthy individuals also annuitize, i.e. adverse selection is reduced. However, the problem that different insured receive a different value for money is even increased by tax incentives. If enhanced annuities are introduced, the percentage of insured who should annuitize further increases. Adverse selection is further reduced and the differences in value for money from annuitizing shrink.

YIN, CHUANCUN; WEN, YUZHEN; ZHAO, YONGXIA. On the optimal dividend problem for a spectrally positive Lévy process. 635-651. In this paper we study the optimal dividend problem for a company whose surplus process evolves as a spectrally positive Lévy process before dividends are deducted. This model includes the dual model of the classical risk model and the dual model with diffusion as special cases. We assume that dividends are paid to the shareholders according to an admissible strategy whose dividend rate is bounded by a constant. The objective is to find a dividend policy so as to maximize the expected discounted value of dividends which are paid to the shareholders until the company is ruined. We show that the optimal dividend strategy is formed by a threshold strategy.

ASTIN Bulletin abstracts:

Reproduced with the permission of ASTIN (Actuarial Studies in Non-Life Insurance) of the International Actuarial Association and now published online by Cambridge Journals of Cambridge University Press:

http://journals.cambridge.org/action/displayJournal?jid=ASB

An archive of past Bulletins from 1958 to 2010 is available free through the IAA website:

http://www.actuaries.org/index.cfm?lang=EN\&DSP=PUBLICATIONS\&ACT=ASTIN_BULLETIN

Members who join ASTIN and AFIR receive and have access to ASTIN Bulletin. Members of the Institute and Faculty of Actuaries can join ASTIN and AFIR by contacting: membership@actuaries. org.uk

Subscription details available from: International Actuarial Association: https://www.actuaries.org/SECTIONS/SECTION_MEMBERSHIP_EN.cfm

Australian Journal of Actuarial Practice

2,2014

ANDREWS, DOUG. What can we learn from population ratios. 47-54. Actuaries and others often use ratios to determine historical changes and to make predictions about future conditions. This paper considers the usefulness of using population ratios to predict the future financial impact on social support systems. I define two common population ratios and show the direction of the predicted financial impact on social support costs of population aging using these ratios. I present the analysis of two researchers, Spijker and MacInnes, and note how their analysis contradicts the predictions indicated by the common population ratios. I consider differences between social support systems with respect to health and long term care and those providing retirement income. I consider two ways in which Sweden is taking steps to make the burden indicated by population ratios more bearable, with respect to retirement income. Unfortunately Sweden's calculation of the 
assets is flawed and so the adjustments required by the ABM are unfairly advantageous to pensioners and unfairly disadvantageous to future contributors. However, a concept developed for the estimation of assets, turnover duration, is useful. I propose two new population ratios, refined to incorporate components of turnover duration, and illustrate this approach using information concerning the Swedish pension system. I propose four recommendations.

ASHER, ANTHONY. Redistribution and capital market impacts of social security retirement systems: principles and scope for actuarial involvement. 13-20. This paper in part responds to Rob Brown's "The essence of social security: debunked myths" in this volume. As in that paper, social security retirement systems (SSRS) refer to arrangements that provide non-labour income to the elderly. It makes the argument that SSRS need actuarial monitoring and spells out the principles that should inform such monitoring. The first two sections identify and suggest principles for addressing the problematic issues of income redistribution and the impact of SSRS on capital markets. Section 3 considers the redistribution implicit in defined benefit (DB) schemes, and how actuaries should play a role in making such redistribution transparent in both DB and defined contribution (DC) arrangements. Section 4 suggests that there is a place for more comprehensive reporting to ensure that the schemes meet their objectives. The fifth section considers the impacts of all types of SSRS on investment markets. There is an obvious actuarial role in the projection of the effect of demographic changes, and. a potentially enhanced role in the governance of the financial system and particularly in much more intensive data collection and analysis. Section 6 expands on the possible role of actuaries in monitoring SSRS and section 7 summarises and concludes.

BROWN, ROBERT L. The essence of social security: debunked myths. 5-12. This paper attempts to focus the definition of a social security system at its most basic level. In doing so, it discovers a number of truths:

1. PAYGO systems are not remarkably different from fully funded systems.

2. Fully funded systems are not demographically immune.

3. Fully funded systems are not inherently more stable than PAYGO systems.

4. The least desirable design for a social security system is an individual account defined contribution system.

DAYKIN, CHRIS D. Sustainability of pension systems in Europe - the demographic challenge. 55-61. Fiscal sustainability of pensions is a serious issue in Europe because of the ageing of the population but there is also concern that reformed pensions may not be adequate. Actuaries have always been seen as major players in employer-sponsored pension schemes and insured pensions but have often not been very visible in commenting on public policy issues concerning the pension system as a whole. This article introduces the work being done by the Actuarial Association of Europe to raise the profile of actuaries with European institutions on the broader policy issues.

GANNON, FRÉDÉRIC; HAMAYON, STÉPHANE; LEGROS, FLORENCE; TOUZÉ, VINCENT. Sustainability of the French first pillar pension scheme (CNAV): assessing automatic balance mechanisms. 33-45. In this paper, we apply two types of automatic balance mechanism (ABM) to the French first pillar pension system for private sector employees (CNAV) [Caisse Nationale d'Assurance Vieillesse]. One is based on a tax gap ratio (TGR-ABM) and the other is the smooth ABM (S-ABM) developed by Gannon, Legros and Touzé (2013) [F. Gannon, \& V. Touzé. (2013). Pension rules and implicit marginal tax rates in France. In Michèle Vanmaele et al. (eds.), 
Proceedings of the 2013 Actuarial and Financial Mathematics Conference, Brussels, 39-44]. Automatic adjustment mechanisms and budget balancing of pension schemes. Paper presented at the AFIR/ERM - PBSS - Life Colloquium, 24-26 June 2013, Lyon, France. Two long-run forecast scenarios over the period 2014-2063 are analysed. The first is optimistic ("benchmark") and assumes a $4.5 \%$ unemployment rate and a $1.5 \%$ productivity growth rate in the long run. The second is more pessimistic ("prudent"), with a $7.5 \%$ unemployment rate and a $1 \%$ productivity growth rate in the long run. For the benchmark (respectively prudent) scenario, a TGR-ABM requires, now and for the next 50 years, a $2.8 \%$ (respectively $6.3 \%$ ) decrease in pensions and a $2.9 \%$ (respectively $6.7 \%$ ) increase in the tax rate. An S-ABM requires, for the benchmark (respectively prudent) scenario, an immediate $1.5 \%$ (respectively $3.6 \%$ ) decrease in pensions and a $1.4 \%$ (respectively $3.5 \%$ ) increase in the tax rate. In the long run (50 years), an S-ABM requires a $4.5 \%$ (respectively $9.1 \%$ ) reduction in pensions and a $4.5 \%$ (respectively $9.1 \%$ ) increase in the tax rate.

HAGEMEJER, KRZYSZTOF; WOODALL, JOHN. How should the adequacy of pension coverage be balanced against financial sustainability? 21-31. In recent decades many countries have "reformed" their contributory pension schemes, generally strengthening the links between benefit entitlements and the contributions paid over members' working lifetimes, but primarily seeking to (re)balance them financially, in the face of strains arising from unfavourable labour market or demographic conditions. The result has been reduced benefit entitlements and levels of coverage, however assessed. The impact has been felt, particularly, by those with shorter, broken careers (due for example to longer spells of unemployment, precarious employment, or family care responsibilities) and with low levels of lifetime earnings. Countries have introduced "automatic" mechanisms which reduce benefits, but without countervailing mechanisms to prevent them from falling below poverty levels. Questions arise, therefore, as to how the adequacy of coverage and benefit levels may be secured, how the non-contributory elements of pension systems should be strengthened, and how much room is left to policy discretion when automatic balancing results in socially undesired outcomes. The issues are illustrated for the countries of the European Union, where extensive statistical data are available, but are important globally. Clearly, actuaries must play a key role in providing the relevant quantitative assessments, and some questions are raised as to the nature of their responsibilities.

Australian Journal of Actuarial Practice (successor to Australian Actuarial Journal) abstracts. Reproduced with the permission of the Institute of Actuaries of Australia.

Access: http://www.actuaries.asn.au/knowledge-bank/journals

E-mail: actuaries@actuaries.asn.au

European Actuarial Journal

$$
4(2), 2014
$$

KALAŠ, MARTIN; CIPRA, TOMÁŠ. Sustainable retirement spending: the Czech case. 365-381. The paper is concerned with retirement planning, in particular with sustainable retirement spending towards the end of the human life cycle, which is a substantial quantitative problem in the pension framework. Some authors have recently successfully used an arithmetic Asian option pricing concept to estimate an individual's probability of retirement ruin under constant spending rates and asset prices driven by the geometric Brownian motion. It was concluded that for an individual with a given investment portfolio, the expected rate of return and volatility of which are known, 
the probability of retirement ruin can be estimated using the reciprocal gamma distribution. We extend this theoretical result to the case, when remaining length of human life follows the Gompertz-Makeham law of mortality. The accuracy of presented approximation is analysed via Monte Carlo simulations. A numerical case study using Czech data is provided, including calculated maximal sustainable spending rates for Czech retirees under various combinations of wealth-to-spending ratios and investment portfolio characteristics. We also present optimal investment strategies for retirees with various risk of ruin tolerances.

KLING, ALEXANDER; RUEZ, FREDERIK; RUß, JOCHEN. The impact of policybolder behavior on pricing, hedging, and hedge efficiency of withdrawal benefit guarantees in variable annuities. 281-314. We analyze the impact of policyholder behavior on pricing, hedging and hedge efficiency of variable annuities with guaranteed lifetime withdrawal benefits. We consider different product designs, market models and approaches for modeling policyholder behavior in our analyses, covering deterministic behavior, behavior depending on the 'moneyness' of the guarantee, and optimal (value maximizing) behavior. First, we assess the risk of mispricing the guarantee due to inaccurate assumptions regarding future policyholder behavior. Comparing products with different ratchet mechanisms, we find that this potential for mispricing is the smallest for the product design with the most valuable ratchet mechanism. We further quantify the impact of different behavior models on the efficiency of the insurer's hedging strategy and the risk that results if the insurer's assumption for policyholder behavior deviates from actual behavior. Our analyses indicate significant differences between the considered products in terms of hedgeability and the sensitivity of the guarantee's value towards policyholder behavior and towards changes in the underlying asset's volatility. Also, we show that a simple path-dependent behavior model may not be suitable to fully assess the risk arising from policyholder behavior.

NATOLSKI, JAN; WERNER, RALF. Mathematical analysis of different approaches for replicating portfolios. 411-435. This paper considers the most popular approaches for the construction of replicating portfolios for life insurance liabilities known as cash flow matching and terminal value matching. Solutions to these construction approaches are derived and compared. It is shown that the (unique) solutions have fair value equal to the fair value of liabilities. Then, the problems are generalized by relaxing the requirement of static replication to allow for dynamic investment strategies in the cash account with zero present value. A relationship between the solutions to these generalized problems is established, which sheds new light on the relation of the original problems. Finally, it is proved that the fair values of the optimal solutions to the generalized problems remain equal to the fair value of liabilities.

PICHLER, ALOIS. Insurance pricing under ambiguity. 335-364. An actuarial model is typically selected by applying statistical methods to empirical data. The actuary employs the selected model then when pricing or reserving an individual insurance contract, as the selected model provides complete knowledge of the distribution of the potential claims. However, the empirical data are random and the model selection process is subject to errors, such that exact knowledge of the underlying distribution is in practice never available. The actuary finds her- or himself in an ambiguous position, where deviating probability measures are justifiable model selections equally well. This paper employs the Wasserstein distance to quantify the deviation from a selected model. The distance is used to justify premiums and reserves, which are based on erroneous model selections. The method applies to the Net Premium Principle, and it extends to the well-established Conditional Tail Expectation and to further, related premium principles. To demonstrate the 
relations and to simplify the computations, explicit formulas for the Conditional Tail Expectation for standard life insurance contracts are provided.

PIGEON, MATHIEU; DE FRAHAN, BRUNO HENRY; DENUIT, MICHEL. Evaluation of the EU proposed farm income stabilisation tool by skew normal linear mixed models. 383-409. The European Commission has introduced new risk management tools in the rural development pillar 2 of the Common Agricultural Policy. One of them consists in providing co-financing support to mutual funds compensating farmers who experience a severe drop in their income. This paper analyses this income stabilisation tool for a region in Belgium by means of a skew normal linear mixed model. Relying on the farm accountancy data network, this analysis focuses on estimating the probability that such a fund would need to intervene and, in that case, the expected amount of each farm income compensation. The predictive distribution of future incomes given past revenues trajectory is derived and used for evaluation purposes. Particular attention is paid to additional requirements that could be imposed to the income stabilisation tool.

PRATSIOVYTYI, MYKOLA; DROZDENKO, VITALIY. Characterization theorems for customer equivalent utility insurance premium calculation principle. 437-451. Characterization theorems for several properties possessed by the customer equivalent utility insurance premium calculation principle are presented. Demonstrated theorems cover cases of additivity, consistency, iterativity, and scale invariance properties. Results are formulated in a form of necessary and sufficient conditions for attainment of the properties imposed on customer's utility function. Obtained theorems are also valid for the customer zero utility premium calculation principle. We also demonstrate that for the customer zero utility principle subjected to pricing of only strictly positive risks, the class of the utility functions producing scale invariant premiums is larger than in the general case.

TOMAS, JULIEN; PLANCHET, FRÉDÉRIC. Constructing entity specific projected mortality table: adjustment to a reference. 247-279. This article presents an operational framework for constructing and validating projected mortality table specific to an insurer. We describe several methods of increasing complexity and the process of validation allowing an insurer to adjust a baseline mortality to get closer to a best estimate assessment of its mortality and longevity risk. They provide to the insurer some latitude of choice while preserving simplicity of implementation for the basic methodology. The methodologies articulate around an iterative procedure allowing to choose parsimoniously the most satisfying one. The process of validation is assessed on three levels. This concerns the proximity between the observations and the model, the regularity of the fit as well as the plausibility and consistency of the mortality trends. Finally, the procedure is illustrated from experience data originating from a French Insurance portfolio.

VAN DEN BROEK, KORNEEL. Long-term insurance products and volatility under the Solvency II Framework. 315-334. Solvency II will become the new regulatory framework for insurance companies in Europe. It sets the capital requirements in function of the insurer's risk exposure at a one-year time horizon. The objective of the paper is to quantify the cost of the volatility in the required capital induced by the Solvency II liability valuation methodology. First, we show that Solvency II will induce large variation in the required capital for illiquid long-term products with guarantees. The volatility of the required capital is larger for policies with a larger maturity. We then introduce a different liability valuation technique specifically for illiquid liabilities. The volatility of the required capital in this model is lower since it only depends on the default component of the credit spread of the backing assets. We prove that this model is market 
consistent. We conclude by estimating the cost of the option, which an insurer could buy to eliminate the extra induced capital volatility. Such option will generate the cash flow necessary to supply the extra required capital resulting from a change in illiquidity spread.

European Actuarial Journal abstracts.

Reproduced with the permission of Springer.

Subscription details available from: http://ink.springer.com/contactus

http://link.springer.com/journal/13385

Geneva Papers on Risk and Insurance

39(3), 2014

BROKEŠOVÁ, ZUZANA; PASTORÁKOVÁ, ERIKA; ONDRUŠKA, TOMÁŠ. Determinants of insurance industry development in transition economies: empirical analysis of Visegrad group data. 471-492. The private insurance industry represents an integral part of all advanced economies. However, in transition economies its role differs. Monopolisation of the industry as well as wide social systems in the era of communistic government, inter alia, led to the reduction in the needs and offers of private insurance. Its importance began to grow after the regime change in 1989. This paper focuses on the examination of areas and factors that influenced the development of the insurance industry in four Central European transition economies: the Czech Republic, Hungary, the Republic of Poland and the Slovak Republic, also known as the Visegrad Four (V4) countries. Based on the results obtained, we were able to confirm that between 1995 and 2010 in V4 countries, the development of insurance markets was fuelled by different determinants from those fuelling the insurance industry in advanced economies. Different results were found for determinants including inflation rate, the age dependency ratio, degree of urbanisation, the social security system and rate of criminality.

DE MOT, JEF; VISSCHER, LOUIS. Efficient court decisions and limiting insurers' right of recourse: the case of custodian liability in the Netherlands and Belgium. 527-544. Custodian liability is the liability for losses caused by an object under a person's control. Although the basic rules regarding custodian liability are quite similar in The Netherlands and Belgium, one major difference exists. Whereas Belgium always applies strict liability, in the Netherlands, strict liability does not apply if the suit is filed by a subrogated party (e.g. an insurer). These parties have to rely on negligence. We examine from an economic perspective whether strict liability or negligence is better suited for custodian liability and consequently also analyse the efficiency of the Dutch limitation on recourse. We examine written law and case law. More specifically, we focus on the question whether courts, by interpreting the concepts of "defect" and of "custodian", place liability on the person who was in the best position to prevent the accident from happening (or to minimise the risk that the accident would happen).

DE MOT, JEF; FAURE, MICHAEL G. Special insurance systems for motor vehicle liability. 569-584. The fact that automobile insurance is compulsory for most drivers in Europe and the United States raises concerns about its affordability and availability. In most legal systems, to mitigate such problems, special facilities have been created, either by policymakers or by insurance companies, to deal with risks that are very difficult to insure or are even considered uninsurable on the commercial market. In this article we (1) provide an overview of special schemes in several European countries, (2) examine the potential advantages of reducing the number of uninsured 
drivers and investigate the influence of the special schemes on the decision of individuals to drive (un)insured, (3) examine the consequences of these schemes for the incentives of drivers and (4) discuss the social costs of the special schemes.

JOBST, ANDREAS A. Systemic risk in the insurance sector: a review of current assessment approaches. 440-470. The following article reviews the recent regulatory efforts in defining systemic risk in the insurance sector and the designation of systemically important insurers. Although current evidence suggests that core insurance activities are unlikely to cause or propagate systemic risk, the characteristics and business models of insurance firms vary by country and might require a more nuanced examination, with a particular focus on non-traditional and/or noninsurance activities. The article also includes the assessment of identified vulnerabilities from liquidity risk in the context of the Bermuda market, which provides valuable insights into systemic risk analysis in the domestic context of an insurance market dominated by non-life underwriting.

LORSON, JONAS; WAGNER, JOËL. Sales efficiency in life insurance: the drivers for growth in the German market. 493-524. German life insurers are facing consolidation tendencies as the major players increase their market share. As a result, insurance companies are being forced to grow to ensure future prosperity. In the past, the industry has shown that growth can be achieved while maintaining profitability. The central question of our research is to detect factors for the generation of new business. In order to determine what drives sales - and thus growth - in the German life insurance industry, we apply different multi-linear regression models. We use panel data from 1998 to 2011 with characteristics of German life insurers and mostly full market coverage. In our modelling, we distinguish between sales success on the business unit level of life insurance and on the level of specific life products. The sales success drivers for pension insurance as well as term life insurance are analysed. By doing so, we determine different significant drivers for sales success, which include the total return granted to policyholders, commissions paid to sales partners, the solvency of the insurer, company (financial) rating and firm size.

PHILIPSEN, NIELS J. Limiting auditors' liability: the case for (and against) EU intervention. 585-597. This paper addresses auditors' liability in the light of the current competition problems in the market for statutory audits and actions taken by the European Commission. First, it will be explained that there is a lack of competition in the market for audits of large and quoted companies. Middle-tier firms are not willing to enter this market, inter alia, because of high litigation risks and problems in the insurance market. Second, Commission Recommendation 2008/437 will be analysed from an economic perspective. Interestingly, the Commission suggests various options for limiting liability, but leaves the choice between those instruments to Member States. The need to limit auditors' liability will be addressed in the context of the economic theory of regulation, with a focus on the European context. The central question, therefore, is whether there is a need for the EU to intervene and whether the existing Recommendation is the right instrument.

PORRINI, DONATELLA. The Italian motor insurance market: will the recent interventions solve the old efficiency problems? 545-568. Among the main European countries, Italy continues to be the one with the highest frequency of accidents and the highest average cost of damages. Moreover, there is a relationship between premiums and compensation costs: insurance premiums follow the trend of accident frequency and the average cost of claims. Therefore, this paper analyses the dynamics of the Italian insurance market in terms of premiums, claims and fraud. It then considers recent public interventions in relation to their efficiency in dealing with the problem 
of the excessively high level of premiums. Finally, an explanation is found for the weakness of competition and the distributional structure of Italian insurance companies.

STOYANOVA, RAYNA; GRÜNDL, HELMUT. Solvency II: a driver for mergers and acquisitions? 417-439. The European insurance industry is awaiting the new EU-wide harmonised Solvency II framework. Before its introduction, it is important to find out which incentive effects can arise from it. Practitioners predict a trend towards consolidation in the insurance sector due to recognition of geographic diversification effects in Solvency II's standard formula. This paper studies whether the new European regulation standards will constitute a driver for mergers and acquisitions in the non-life insurance sector. We identify situations in which consolidation becomes profitable. Our results indicate that the Solvency II framework may lead to an enhanced geographic restructuring wave. However, the profitability of this restructuring depends strongly on the correct estimation of costs and the characteristics of the consolidation partner chosen.

Geneva Papers on Risk and Insurance

$$
\text { 39(4), } 2014
$$

BROWNE, MARK J; ZHOU-RICHTER, TIAN. Lemons or cherries? Asymmetric information in the German private long-term care insurance market. 603-624. This study provides evidence of the presence of asymmetric information in the German long-term care (LTC) insurance market. While certain private information - individuals' pessimism level and preference for insurance contributes to advantageous selection, the major source of adverse selection - individuals' self-assessed high LTC risk - switches the final correlation between insurance and risk to one that is significantly positive. In addition, the study reveals that although individuals' self-assessment of poor health predicts their future care needs very well, such assessments are not necessarily reflected in insurance demand. The results from this study could assist insurers in better understanding and managing LTC risk.

DROR, DAVID M; FIRTH, LUCY A. The demand for (micro) health insurance in the informal sector. 693-711. We identify the need for a theory of demand for health insurance suited to the informal sector in low- and middle income countries (LMIC) where some 3 billion people lack health cover. Excluded from formal governance structures, they rely on informal arrangements by which rules-in-use shape choices, behaviours and decisions. We explore the fundamental assumptions of standard economic theories of demand for health insurance in the light of arguments from the literature and field evidence. We show that the assumptions are largely inconsistent with the context of poverty and informality. And we propose a new theory based on assumptions better suited to the context of informality and poverty. Our major conclusion is that, in order to grow the demand for health insurance in the informal sector in LMIC, it is first necessary to strengthen ground-up governance consistent with group-based decision-making under local conditions.

ENCINOSA, WILLLIAM; MEYERHOEFER, CHAD; ZUVEKAS, SAMUEL; DU, DONGYI. The impact of direct-to-consumer advertising on health insurance markets. 749-767. Directto-consumer advertising (DTCA) for drugs has increased from US\$200 million in 1997 to US\$4 billion in 2011. While studies show that DTCA impacts the patient-physician relationship, little is known of the effect of DTCA on health insurance markets. We test whether DTCA raises the costs in these markets or makes the markets more efficient in drug pricing. Across 212 markets, we 
examine the impact of DTCA on insurers' negotiated prices for 166 drugs. Controlling for unobserved pharmacy and pharmacy benefit manager attributes, as well as manufacturer advertising market selection effects, we find that an increase in a manufacturer's DTCA spending lowers insurer prices and reduces insurance market price dispersion. These competitive effects intensify as DTCA competition increases between drug manufacturers.

GOVENDER, VELOSHNEE; ATAGUBA, JOHN E; ALABA, OLUFUNKE A. Health insurance coverage within households: the case of private health insurance in South Africa. 712-726. Private health insurance coverage within households is declining in South Africa (SA). This raises concerns in a context of growing support both in SA and internationally for universal health coverage (UHC). This paper attempts to advance our understanding of coverage patterns within partially insured households (i.e. having at least one, but not all members, being insured). This paper was guided by the following questions: (1) What factors are associated with some household members being insured? And (2) who are excluded? Drawing from a nationally representative household survey, it was found that partially insured households differed from completely insured households across a range of demographic and socio-economic factors. Significantly, there was a relationship bias; relationship with the household head was an important predictor of access to insurance within partially insured households. As the drive towards UHC gains momentum in SA and other countries, there is a need to conduct similar intra-household-level empirical research.

MAYHEW, LES; SMITH, DAVID. Personal Care Savings Bonds: a new way of saving towards social care in later life. 668-692. An ageing population ushers in a completely new era requiring society to find new solutions to funding social care and looking after older people. This is not a temporary issue that will go away and there are no quick economic fixes. In the UK it is estimated that the population aged $75+$ will double from 5 million to 10 million by 2040 . Financial building blocks are needed to pay for social care that will be sustained for decades and provide extra security for the individual. This paper proposes a new savings product called Personal Care Savings Bonds (PCSBs), which are designed to encourage saving for social care by providing extra money at the time of greatest financial need. PCSBs are likely to be attractive to older people who have only a basic pension and modest savings, but also to other age groups, as they not only attract interest but also pay prizes. Based on reasonable assumptions, the paper shows how the fund could build into a substantial investment worth $£ 70$ billion with regular monthly prize pay-outs. In concept they are somewhat similar to Premium Bonds, another UK personal savings product that has been successfully operating since 1956 .

OUTREVILLE, JEAN-FRANÇOIS. The meaning of risk? Insights from the Geneva Risk and Insurance Review. 768-781. The Geneva Association and European Group of Risk and Insurance Economists, through publications like the Geneva Risk and Insurance Review, serve as a catalyst for progress in the understanding of risk and insurance matters. The purpose of this paper is to review and summarise some of the papers published in 2012 and 2013 that could help us to understand what risk is and the implications for the insurance industry. Although the idea of risk may be difficult to conceptualise, risk is of considerable importance for the functioning of all economies and economic agents. Risk aversion, adverse selection, asymmetric information and the performance of insurance markets are important issues that are regularly discussed in the review. These issues are of particular relevance for insurers and the proper functioning of insurance markets.

QIN, XUEZHENG; LU, TIANYI. Does health insurance lead to ex ante moral hazard? Evidence from China's new rural cooperative medical scheme. 625-650. This paper examines whether 
participating in the New Rural Cooperative Medical Scheme (NRCMS), a publicly subsidised health insurance programme in rural China, encourages individuals to engage in risky health behaviours. Despite its rapidly increasing coverage rate, relatively little attention has been paid to the impact of NRCMS on the lifestyle choices of its enrollees. On the basis of the 2000-2009 longitudinal data from the China Health and Nutrition Survey (CHNS), we find that NRCMS participation has a statistically significant (although quantitatively small) impact on people's tendency towards smoking, heavy drinking (among males), spending time in sedentary activities, consuming high-calorie food and being overweight. The increase in these unhealthy lifestyles in turn leads to elevated disease risks, indicating that insurance-induced, "ex ante moral hazard" is present in rural China. The findings are robust to the variation in model specification and sample selection, as well as to the introduction of an instrumental variable that controls the endogeneity of insurance participation. Our results provide implications on reforming the pricing and administration practice of China's largest health insurance campaign and on evaluating public insurance schemes in other developing countries.

XU, XIAN; ZWEIFEL, PETER. Bilateral intergenerational moral hazard: empirical evidence from China. 651-667. Bilateral intergenerational moral hazard (BIMH) has been considered as one of the most important reasons for the sluggish development of private long-term care (LTC) insurance. On the one hand, the parent, who relies on child effort to avoid admission to the nursing home, may abstain from purchasing LTC insurance. On the other hand, buying LTC insurance coverage serves to protect the available bequest from the cost of LTC, thus weakening child interest in providing informal care as a substitute for formal LTC. In this paper, we investigate whether BIMH with respect to LTC exists in China. A survey conducted in October 2012 in Shanghai suggests that respondents may well exhibit BIMH as predicted by Courbage and Zweifel. However, contrary to their predictions, neither a decrease in parental wealth nor a decrease in the child's expected inheritance are found to trigger net BIMH effects. These findings have important implications both for insurance companies planning to develop LTC products and for Chinese public policy concerning LTC.

YOO, MINKYOUNG. Private health insurance and risk protection: changes in out-of-pocket medical spending, 2001 and 2011. 727-748. Changes in the cost-sharing provisions of employment-sponsored health insurance in the 2000s were designed to control U.S. health-care spending. However, such provisions may also increase the financial burden on families who need medical care and may differentially affect families according to their socioeconomic characteristics and the health status of family members. Additionally, changes in cost sharing may alter the entire shape of the out-of-pocket spending distribution. Using quantile regressions, I assess whether the distribution of out-of-pocket spending and hence the risk-protection function of private insurance has been affected by such changes. The empirical results reveal that families who are likely to incur higher health-care spending because of family members' existing health conditions were most affected by changes in cost sharing, while families with older policyholders at higher percentiles of the out-of-pocket spending distribution experienced decreases in such spending.

Geneva Papers on Risk and Insurance abstracts.

Reproduced with the permission of Palgrave MacMillan:

http://www.palgrave-journals.com/gpp/index.html

Subscription details available from: Palgrave Macmillan Subscription Department Tel:+44 (0)1256

357893, subscriptions@palgrave.com 
Geneva Risk and Insurance Review

39(1), 2014

GRAFTON, QUENTIN; KOMPAS, TOM; LONG, NGO VAN. Increase in risk and its effects on welfare and optimal policies in a dynamic setting: The case of global pollution. 40-64. This paper studies the effects of an increase in risk on welfare and optimal policies in a stochastic dynamic model of global pollution. In a first step, we focus on the case of a single decision maker, and make use of an approach pioneered by Kimball (2014) for studying the impact of a marginal change in risk in optimal stochastic control models. Using a simple model with only one state variable and one control variable, we show how the optimal carbon tax responds to an increase in risk. It is found that the third derivative of the decay function of the stock of pollution may play a decisive role. In a second step, we investigate the extent to which Kimball's approach may be extended to the case of stochastic dynamic games. We show how strategic interactions complicate the task of evaluating the effects of an increase in risk. Interestingly, in a dynamic model of the tragedy of the commons, we find that an increase in risk can increase welfare even though all agents are risk averse. The reason is that higher risk can cause agents to be more conservative, and this mitigates the tragedy of the commons.

HUANG, RACHEL J; MUERMANN, ALEXANDER; TZENG, LARRY Y. Regret and regulation. 65-89. We analyse the welfare effect of governmental regulation for individuals who consider anticipated regret in their decision-making process. Although governmental policies by directing choice, distort individual decisions in the private market, they can alleviate individuals' pain associated with the feeling of regret. We analyse this trade-off and provide conditions under which the implied reduction of regret justifies regulation. Furthermore, we demonstrate our findings on tax deduction for non-insured losses, a well-studied social policy in insurance. Last, we consider heterogenous individuals and alternative social welfare functions and show that our results hold in these extended settings.

KIMBALL, MILES S. The effect of uncertainty on optimal control models in the neighbourhood of a steady state. 2-39. For both discrete and continuous time this paper derives the Taylor approximation to the effect of uncertainty (in the simple sense of risk, not Knightian uncertainty) on expected utility and optimal behaviour in stochastic control models when the uncertainty is small enough that one can focus on only the first term that involves uncertainty. There is a close and illuminating relationship between the discrete-time and continuous-time results. The analysis makes it possible to spell out a tight connection between the behaviour of a dynamic stochastic general equilibrium model and the corresponding perfect foresight model. However, the quantitative analytics of the stochastic model local to a certainty model calls for a more thorough investigation of the nearby certainty model than is typically undertaken.

OLIVELLA, PAU; SCHROYEN, FRED. Multidimensional screening in a monopolistic insurance market. 90-130. We consider a population of individuals who differ in two dimensions, their risk type (expected loss) and their risk aversion, and solve for the profit-maximising menu of contracts that a monopolistic insurer puts out on the market. Our findings are threefold. First, it is never optimal to fully separate all the types. Second, if heterogeneity in risk aversion is sufficiently high, then some high-risk individuals (the risk-tolerant ones) will obtain lower coverage than some lowrisk individuals (the risk-averse ones). Third, because women tend to be more risk averse than men (in that the risk aversion distribution for women first-order stochastically dominates that for men), gender discrimination may lead to a Pareto improvement. 
Geneva Risk and Insurance Review

39(2), 2014

DIONNE, GEORGES; ROTHSCHILD, CASEY G. Economic effects of risk classification bans. 184-221. Risk classification refers to the use of observable characteristics by insurers to group individuals with similar expected claims, to compute the corresponding premiums, and thereby to reduce asymmetric information. Permitting risk classification may reduce informational asymmetry-induced adverse selection and improve insurance market efficiency. It may also have undesirable equity consequences and undermine the implicit insurance against reclassification risk, which legislated restrictions on risk classification could provide. We use a canonical insurance market screening model to survey and to extend the risk classification literature. We provide a unified framework for analysing the economic consequences of legalised vs banned risk classification, both in static-information environments and in environments in which additional information can be learned, by either side of the market, through potentially costly tests.

GARVEN, JAMES R; HILLIARD, JAMES I; GRACE, MARTIN F. Adverse selection in reinsurance markets. 222-253. This paper looks for evidence of adverse selection in the relationship between primary insurers and reinsurers. We test the implications of a model in which informational asymmetryand therefore, its negative consequences-decline over time. Our tests involve a data panel consisting of U.S. property-liability insurance firms that reported to the National Association of Insurance Commissioners during the period 1993-2012. We find that the amount of reinsurance, insurer profitability, and insurer credit quality all increase with the tenure of the insurer-reinsurer relationship.

HENDREN, NATHANIEL. Unravelling vs Unravelling: A memo on competitive equilibriums and trade in insurance markets. 176-183. Both Akerlof (1970) and Rothschild and Stiglitz (1976) show that insurance markets may "unravel". This memo clarifies the distinction between these two notions of unravelling in the context of a binary loss model of insurance. I show that the two concepts are mutually exclusive occurrences. Moreover, I provide a regularity condition under which the two concepts are exhaustive of the set of possible occurrences in the model. Akerlof unravelling characterises when there are no gains to trade; Rothschild and Stiglitz unravelling shows that the standard notion of competition (pure strategy Nash equilibrium) is inadequate to describe the workings of insurance markets when there are gains to trade.

MIMRA, WANDA; WAMBACH, ACHIM. New developments in the theory of adverse selection in competitive insurance. 136-152. We provide an overview of the paths taken to understand existence and efficiency of equilibrium in competitive insurance markets with adverse selection since the seminal work by Rothschild and Stiglitz (1976). A stream of recent work reconsiders the strategic foundations of competitive equilibrium by carefully modelling the market game.

PICARD, PIERRE. Participating insurance contracts and the Rothschild-Stiglitz equilibrium puzzle. 153-175. We extend the Rothschild-Stiglitz (RS) insurance market model with adverse selection by allowing insurers to offer either non-participating or participating policies, that is, insurance contracts with policy dividends or supplementary calls for premium. It is shown that an equilibrium always exists in such a setting. Participating policies act as an implicit threat that dissuades deviant insurers who aim to attract low-risk individuals only. The model predicts that the mutual corporate form should be prevalent in insurance markets where second-best Pareto efficiency requires cross-subsidisation between risk types. 
SPINDLER, MARTIN. Econometric methods for testing for asymmetric information: A comparison of parametric and nonparametric methods with an application to hospital daily benefits. 254-266. Since Chiappori and Salanié, testing for asymmetric information has become tantamount to testing for a positive relation between risk and coverage which is predicted by (equilibrium) models for adverse selection and moral hazard. In this paper we review parametric tests and a recently developed nonparametric test ( $\mathrm{Su}$ and Spindler) and discuss the underlying assumptions. As an illustrative example, we apply the tests to hospital daily benefits which is part of the accident/ disability insurance. We compare the results and show that the pattern of asymmetric information is mixed. The main finding is that we detect asymmetric information for low insured sums, but not for high insured sums which is a surprising result. We can also show that in certain ranges both types of test deliver similar results, while under certain circumstances, approaches using aggregation to binary variables might run into difficulties.

Geneva Risk and Insurance Review abstracts.

Reproduced with the permission of Palgrave MacMillan:

http://www.palgrave-journals.com/grir/index.html

Subscription details available from: Palgrave Macmillan Subscription Department Tel: +44 (0)1256 357893, subscriptions@palgrave.com

Insurance: Mathematics \& Economics

57,2014

BARTH, ANDREA; MORENO BROMBERG, SANTIAGO. Optimal risk and liquidity management with costly refinancing opportunities. 31-45. In this paper we study risk and liquidity management decisions within an insurance firm. Risk management corresponds to decisions regarding proportional reinsurance, whereas liquidity management has two components: distribution of dividends and costly equity issuance. Contingent on whether proportional or fixed costs of reinvestment are considered, singular stochastic control or stochastic impulse control techniques are used to seek strategies that maximize the firm value. We find that, in a proportional-costs setting, the optimal strategies are always mixed in terms of risk management and refinancing. In contrast, when fixed issuance costs are too high relative to the firm's profitability, optimal management does not involve refinancing. We provide analytical specifications of the optimal strategies, as well as a qualitative analysis of the interaction between refinancing and risk management.

BERENTSEN, GEIR DRAGE; STØVE, BÅRD; TJØSTHEIM, DAG; NORDBØ, TOMMY. Recognizing and visualizing copulas: an approach using local Gaussian approximation. 90-103. In this paper we examine the relationship between a newly developed local dependence measure, the local Gaussian correlation, and standard copula theory. We are able to describe characteristics of the dependence structure in different copula models in terms of the local Gaussian correlation. Further, we construct a goodness-of-fit test for bivariate copula models. An essential ingredient of this test is the use of a canonical local Gaussian correlation and Gaussian pseudo-observations which make the test independent of the margins, so that it is a genuine test of the copula structure. A Monte Carlo study reveals that the test performs very well compared to a commonly used alternative test. We also propose two types of diagnostic plots which can be used to investigate the cause of a rejected null. Finally, our methods are applied to a "classical" insurance data set. 
CAI, JUN; LEMIEUX, CHRISTIANE; LIU, FANGDA. Optimal reinsurance with regulatory initial capital and default risk. 13-24. In a reinsurance contract, a reinsurer promises to pay the part of the loss faced by an insurer in exchange for receiving a reinsurance premium from the insurer. However, the reinsurer may fail to pay the promised amount when the promised amount exceeds the reinsurer's solvency. As a seller of a reinsurance contract, the initial capital or reserve of a reinsurer should meet some regulatory requirements. We assume that the initial capital or reserve of a reinsurer is regulated by the value-at-risk $(\mathrm{VaR})$ of its promised indemnity. When the promised indemnity exceeds the total of the reinsurer's initial capital and the reinsurance premium, the reinsurer may fail to pay the promised amount or default may occur. In the presence of the regulatory initial capital and the counterparty default risk, we investigate optimal reinsurance designs from an insurer's point of view and derive optimal reinsurance strategies that maximize the expected utility of an insurer's terminal wealth or minimize the VaR of an insurer's total retained risk. It turns out that optimal reinsurance strategies in the presence of the regulatory initial capital and the counterparty default risk are different both from optimal reinsurance strategies in the absence of the counterparty default risk and from optimal reinsurance strategies in the presence of the counterparty default risk but without the regulatory initial capital.

\section{CHRISTIANSEN, MARCUS C; DENUIT, MICHEL; DHAENE, JAN. Reserve-dependent benefits} and costs in life and health insurance contracts. 132-137. Premiums and benefits associated with traditional life insurance contracts are usually specified as fixed amounts in policy conditions. However, reserve-dependent surrender values and reserve-dependent expenses are common in insurance practice. The famous Cantelli theorem in life insurance ensures that under appropriate assumptions surrendering can be ignored in reserve calculations provided that the surrender payment equals the accumulated reserve. In this paper, more complex reserve-dependent payment patterns are considered, in line with insurance practice. Explicit formulas are derived for the corresponding reserve.

DUTANG, CHRISTOPHE; GOEGEBEUR, YURI; GUILLOU, ARMELLE. Robust and biascorrected estimation of the coefficient of tail dependence. 46-57. We introduce a robust and asymptotically unbiased estimator for the coefficient of tail dependence in multivariate extreme value statistics. The estimator is obtained by fitting a second order model to the data by means of the minimum density power divergence criterion. The asymptotic properties of the estimator are investigated. The efficiency of our methodology is illustrated on a small simulation study and by a real dataset from the actuarial context.

GUAN, GUOHUI; LIANG, ZONGXIA. Optimal management of DC pension plan in a stochastic interest rate and stochastic volatility framework. 58-66. This paper investigates an optimal investment strategy of DC pension plan in a stochastic interest rate and stochastic volatility framework. We apply an affine model including the Cox-Ingersoll-Ross (CIR) model and the Vasicek mode to characterize the interest rate while the stock price is given by the Heston's stochastic volatility (SV) model. The pension manager can invest in cash, bond and stock in the financial market. Thus, the wealth of the pension fund is influenced by the financial risks in the market and the stochastic contribution from the fund participant. The goal of the fund manager is, coping with the contribution rate, to maximize the expectation of the constant relative risk aversion (CRRA) utility of the terminal value of the pension fund over a guarantee which serves as an annuity after retirement. We first transform the problem into a single investment problem, then derive an explicit solution via the stochastic programming method. Finally, the numerical analysis is given to show the impact of financial parameters on the optimal strategies. 
KALUSZKA, MAREK; OKOLEWSKI, ANDRZEJ. A note on multiple life premiums for dependent lifetimes. 25-30. We study the properties of multiple life annuity and insurance premiums for general symmetric and survival statuses in the case when the joint distribution of future lifetimes has a dependence structure belonging to some nonparametric neighbourhood of independence. The size of the neighbourhood is controlled by a single parameter, which enables us to model really weak as well as stronger dependencies. We provide bounds on the difference of multiple life premiums for vectors of dependent and independent future lifetimes with the same univariate marginal distributions. Each such upper bound can be treated as a premium loading related to the strength of lifetimes' dependence.

LI, LUJUN; YUEN, K C; YANG, JINGPING. Distorted Mix Method for constructing copulas with tail dependence. 77-89. This paper introduces a method for constructing copula functions by combining the ideas of distortion and convex sum, named Distorted Mix Method. The method mixes different copulas with distorted margins to construct new copula functions, and it enables us to model the dependence structure of risks by handling the central and tail parts separately. By applying the method we can modify the tail dependence of a given copula to any desired level measured by tail dependence function and tail dependence coefficients of marginal distributions. As an application, a tight bound for asymptotic Value-at-Risk of order statistics is obtained by using the method. An empirical study shows that copulas constructed by this method fit the empirical data of SPX 500 Index and FTSE 100 Index very well in both central and tail parts.

RECCHIONI, MARIA CRISTINA; SCREPANTE, F. A bybrid method to evaluate pure endowment policies: Crédit Agricole and ERGO Index linked policies. 114-124. An empirical method to evaluate pure endowment policies is proposed. The financial component of the policies is described using the time dependent Black Scholes model and making a suitable choice for its time dependent parameter functions. Specifically, the integral of the time dependent risk free interest rate is modeled using an extension of the Nelson and Siegel yield curve (see Dielbold and Li, 2006) [Dielbold, F. X., Li, C. (2006). Forecasting the term structure of government bond yields. Journal of Econometrics (2006) 130: 337-364]. The time dependent volatility is expressed using two different models. One of these is based on an extension of the Nelson and Siegel model (Dielbold and $\mathrm{Li}, 2006$ ), while the other assumes that the volatility is a piecewise function with respect to the time variable. The demographic component is modeled using a generalization of the geometric Brownian mean reverting Gompertz model while an asymptotic formula for survival probability is derived when the mortality risk volatility is small. The method has been tested on two policies. In these the risk free interest rate parameters are calibrated using the one-month, three-month, six-month, oneyear, three-year and five-year US treasury constant maturity yields and the parameters of the volatility are calibrated using the VSTOXX volatility indices. The choice of the data employed in the calibration depends on the policy to be evaluated. The performance of the method is established comparing the observed values of the policies with the values obtained using this method.

SHEN, YANG; ZENG, YAN. Optimal investment-reinsurance with delay for mean-variance insurers: a maximum principle approach. 1-12. This paper is concerned with an optimal investment and reinsurance problem with delay for an insurer under the mean-variance criterion. A three-stage procedure is employed to solve the insurer's mean-variance problem. We first use the maximum principle approach to solve a benchmark problem. Then applying the Lagrangian duality method, we derive the optimal solutions for a variance-minimization problem. Based on these solutions, we finally obtain the efficient strategy and the efficient frontier of the insurer's mean-variance problem. Some numerical examples are also provided to illustrate our results. 
SWISHCHUK, ANATOLIY; TERTYCHNYI, MAKSYM; ELLIOTT, ROBERT. Pricing currency derivatives with Markov-modulated Lévy dynamics. 67-76. Using a Lévy process we generalize formulas in Bo et al. (2010) [L. Bo, Y. Wang, X. Yang, Markov-modulated jump-diffusion for currency option pricing, Insurance Mathematics \& Economics (2010) 46: 461-469] for the Esscher transform parameters for the log-normal distribution which ensure that the martingale condition holds for the discounted foreign exchange rate. Using these values of the parameters we find a risk-neural measure and provide new formulas for the distribution of jumps, the mean jump size, and the Poisson process intensity with respect to this measure. The formulas for a European call foreign exchange option are also derived. We apply these formulas to the case of the logdouble exponential distribution of jumps. We provide numerical simulations for the European call foreign exchange option prices with different parameters.

WANG, MIN. Capital allocation based on the Tail Covariance Premium Adjusted. 125-131. The current Solvency II process makes risk capital allocation to different business lines more and more important. This paper considers two business lines with the exponential loss distributions linked by a Farlie-Gumbel-Morgenstern (FGM) copula, modelling the dependence between them. As an allocation principle we use the Tail Covariance Premium Adjusted and obtain expressions for the allocation to the two business lines.

YOU, YINPING; LI, XIAOHU. Optimal capital allocations to interdependent actuarial risks. 104-113. This paper further studies the capital allocation concerning mutually interdependent random risks. In the context of exchangeable random risks, we establish that risk-averse insurers incline to evenly distribute the total capital among multiple risks. For risk-averse insurers with decreasing convex loss functions, we prove that more capital should be allocated to the risk with the larger reversed hazard rate when risks are coupled by an Archimedean copula. Also, sufficient conditions are developed to exclude the worst capital allocations for random risks with some specific Archimedean copulas.

Insurance: Mathematics \& Economics

58,2014

BAIONE, FABIO; LEVANTESI, SUSANNA. A health insurance pricing model based on prevalence rates: application to critical illness insurance. 174-184. The Italian health insurance market is currently undersized. The paucity of assured data and the discontinuous statistical surveys carried out by the National Institute of Statistics (ISTAT) represent one of the main obstacles to the insurance market development. The paper sets forth a parametric model to estimate technical basis for health insurance policies when data are limited and only aggregated information on mortality and morbidity is available. The probabilistic framework is based on a multiple state continuous and time inhomogeneous Markov model. We provide an estimate of transition intensities from the healthy state to the sickness state when only prevalence rates of sickness are available, according to an extension and modification of the methodology proposed in Olivieri (1996) [A. Olivieri, Sulle basi tecniche per le coperture Long Term Care, Giornale dell'Istituto Italiano degli Attuari (1996) 49: 87-116] for Long Term Care insurance. We assume that mortality intensity of both healthy and sick lives is modelled by two independent Gompertz-Makeham models.

BAYRAKTAR, ERHAN; PROMISLOW, S DAVID; YOUNG, VIRGINIA R. Purchasing life insurance to reach a bequest goal. 204-216. We determine how an individual can use life insurance 
to meet a bequest goal. We assume that the individual's consumption is met by an income from a job, pension, life annuity, or Social Security. Then, we consider the wealth that the individual wants to devote towards heirs (separate from any wealth related to the afore-mentioned income) and find the optimal strategy for buying life insurance to maximize the probability of reaching a given bequest goal. We consider life insurance purchased by a single premium, with and without cash value available. We also consider irreversible and reversible life insurance purchased by a continuously paid premium; one can view the latter as (instantaneous) term life insurance.

BELLES-SAMPERA, JAUME; GUILLÉN, MONTSERRAT; SANTOLINO, MIGUEL. GlueVaR risk measures in capital allocation applications. 132-137. GlueVaR risk measures defined by Belles-Sampera et al. (2014) [J. Belles-Sampera, M. Guillén, M. Santolino, Beyond Valueat-Risk: GlueVaR distortion risk measures, Risk Analysis (2014) 34(1): 121-134] generalize the traditional quantile-based approach to risk measurement, while a subfamily of these risk easures has been shown to satisfy the tail-subadditivity property. In this paper we show how GlueVaR risk measures can be implemented to solve problems of proportional capital allocation. In addition, the classical capital allocation framework suggested by Dhaene et al. (2012) [J. Dhaene, A. Tsanakas, E. A. Valdez, S. Vanduffel, Optimal capital allocation principles, Journal of Risk and Insurance (2012) 79(1): 1-28] is generalized to allow the application of the Value-at-Risk (VaR) measure in combination with a stand-alone proportional allocation criterion (i.e., to accommodate the Haircut allocation principle). Two new proportional capital allocation principles based on GlueVaR risk measures are defined. An example based on insurance claims data is presented, in which allocation solutions with tail-subadditive risk measures are discussed.

BOLANCÉ, CATALINA; BAHRAOUI, ZUHAIR; ARTÍS, MANUEL. Quantifying the risk using copulae with nonparametric marginals. 45-56. We show that copulae and kernel estimation can be mixed to estimate the risk of an economic loss. We analyze the properties of the Sarmanov copula. We find that the maximum pseudo-likelihood estimation of the dependence parameter associated with the copula with double transformed kernel estimation to estimate marginal cumulative distribution functions is a useful method for approximating the risk of extreme dependent losses when we have large data sets. We use a bivariate sample of losses from a real database of auto insurance claims.

CHEN, ZHIQIANG; PELSSER, ANTOON; PONDS, EDUARD H M. Evaluating the UK and Dutch defined-benefit pension policies using the holistic balance sheet framework. 89-102. This paper compares the UK and Dutch occupational defined-benefit pension policies using the holistic balance sheet (HBS) framework. The UK DB pension system differs from the Dutch one in terms of the steering tools and adjustment mechanisms. In addition to the sponsor guarantee, the UK system has the protection from the Pension Protection Fund (PPF) that guarantees DB pension schemes' funding shortfalls if the sponsors of the schemes are insolvent. The paper first introduces a multi-period model called value-based ALM to value the embedded options implied by both UK and Dutch pension policies and build the HBS. The HBS framework allows us to have a holistic view on the real and contingent assets and liabilities of a pension scheme and evaluate the impact of introducing a new policy for the stakeholders of the pension scheme. Then, we compare the results of a typical UK policy with a typical Dutch one. The comparison suggests the UK policy is better for participants but worse for the sponsor compared to the Dutch policy. The UK policy is more generous in indexation and participants do not have the burden to contribute to the funding recovery of the pension scheme. The PPF provides protection of the benefits up to a certain level if 
the sponsor is insolvent, thus, participants in a scheme with a UK pension policy are exposed to limited downside risk. On the other hand, the sponsor of the pension scheme with the UK policy shoulders a heavier burden to contribute to the recovery of the pension funding shortfalls than that of the pension scheme with the Dutch policy.

CHIARELLA, CARL; DA FONSECA, JOSÉ; GRASSELLI, MARTINO. Pricing range notes within Wishart affine models. 193-203. We provide analytic pricing formulas for Fixed and Floating Range Accrual Notes within the multifactor Wishart affine framework which extends significantly the standard affine model. Using estimates for three short rate models, two of which are based on the Wishart process whilst the third one belongs to the standard affine framework, we price these structured products using the FFT methodology. Thanks to the Wishart tractability the hedge ratios are also easily computed. As the models are estimated on the same dataset, our results illustrate how the fit discrepancies (meaning differences in the likelihood functions) between models translate in terms of derivatives pricing errors, and we show that the models can produce different price evolutions for the Range Accrual Notes. The differences can be substantial and underline the importance of model risk both from a static and a dynamic perspective. These results are confirmed by an analysis performed at the hedge ratios level.

COQUERET, GUILLAUME. Second order risk aggregation with the Bernstein copula. 150-158. We analyze the tail of the sum of two random variables when the dependence structure is driven by the Bernstein family of copulas. We consider exponential and Pareto distributions as marginals. We show that the first term in the asymptotic behavior of the sum is not driven by the dependence structure when a Pareto random variable is involved. Consequences on the Value-at-Risk are derived and examples are discussed.

DELONG, LUKASZ. Pricing and hedging of variable annuities with state-dependent fees. 24-33. We investigate the problem of pricing and hedging variable annuity contracts for which the fee deducted from the policyholder's account depends on the account value. It is believed that statedependent fees are beneficial to policyholders and insurers since they reduce policyholders' incentives to lapse the policies and match the costs incurred by policyholders with the pay-offs received from embedded guarantees. We consider an incomplete financial market which consists of two risky assets modelled with a two-dimensional Lévy process. One of the assets is a security which can be traded by the insurer, and the second asset is a security which is the underlying fund for the variable annuity contract. In our model we derive an equation from which the fee for the guaranteed benefit can be calculated and we characterize a strategy which allows the insurer to hedge the benefit. To solve the pricing and hedging problem in an incomplete financial market we apply a quadratic objective.

FUNG, MAN CHUNG; IGNATIEVA, KATJA; SHERRIS, MICHAEL. Systematic mortality risk: an analysis of guaranteed lifetime withdrawal benefits in variable annuities. 103-115. Guaranteed lifetime withdrawal benefits (GLWB) embedded in variable annuities have become an increasingly popular type of life annuity designed to cover systematic mortality risk while providing protection to policyholders from downside investment risk. This paper provides an extensive study of how different sets of financial and demographic parameters affect the fair guaranteed fee charged for a GLWB as well as the profit and loss distribution, using tractable equity and stochastic mortality models in a continuous time framework. We demonstrate the significance of parameter risk, model risk, as well as the systematic mortality risk component underlying the guarantee. We quantify how different levels of equity exposure chosen by the policyholder 
affect the exposure of the guarantee providers to systematic mortality risk. Finally, the effectiveness of a static hedge of systematic mortality risk is examined allowing for different levels of equity exposure.

GUELMAN, LEO; GUILLÉN, MONTSERRAT; PÉREZ-MARÍN, ANA M. A survey of personalized treatment models for pricing strategies in insurance. 68-76. We consider a model for price calculations based on three components: a fair premium; price loadings reflecting general expenses and solvency requirements; and profit. The first two components are typically evaluated on a yearly basis, while the third is viewed from a longer perspective. When considering the value of customers over a period of several years, and examining policy renewals and cross-selling in relation to price adjustments, many insurers may prefer to reduce their short-term benefits so as to focus on their most profitable customers and the long-term value. We show how models of personalized treatment learning can be used to select the policy holders that should be targeted in a company's marketing strategies. An empirical application of the causal conditional inference tree method illustrates how best to implement a personalized cross-sell marketing campaign in this framework.

GUO, WENJING. Optimal portfolio choice for an insurer with loss aversion. 217-222. The problem of optimal investment for an insurance company attracts more attention in recent years. In general, the investment decision maker of the insurance company is assumed to be rational and risk averse. This is inconsistent with non fully rational decision-making way in the real world. In this paper we investigate an optimal portfolio selection problem for the insurer. The investment decision maker is assumed to be loss averse. The surplus process of the insurer is modeled by a Lévy process. The insurer aims to maximize the expected utility when terminal wealth exceeds his aspiration level. With the help of martingale method, we translate the dynamic maximization problem into an equivalent static optimization problem. By solving the static optimization problem, we derive explicit expressions of the optimal portfolio and the optimal wealth process.

KARABEY, UGUR; KLEINOW, TORSTEN; CAIRNS, ANDREW J G. Factor risk quantification in annuity models. 34-45. Calculation of risk contributions of sub-portfolios to total portfolio risk is essential for risk management in insurance companies. Thanks to risk capital allocation methods and linearity of the loss model, sub-portfolio (or position) contributions can be calculated efficiently. However, factor risk contribution theory in non-linear loss models has received little interest. Our concern is the determination of factor risk contributions to total portfolio risk where portfolio risk is a non-linear function of factor risks. We employ different approximations in order to convert the non-linear loss model into a linear one. We illustrate the theory on an annuity portfolio where the main factor risks are interest-rate risk and mortality risk.

LANDRIAULT, DAVID; WILLMOT, GORDON E; XU, DI. On the analysis of time dependent claims in a class of birth process claim count models. 168-173. An integral representation is derived for the sum of all claims over a finite interval when the claim value depends upon its incurral time. These time dependent claims, which generalize the usual compound model for aggregate claims, have insurance applications involving models for inflation and payment delays. The number of claims process is assumed to be a (possibly delayed) nonhomogeneous birth process, which includes the Poisson process, contagion models, and the mixed Poisson process, as special cases. Known simplified compound representations in these special cases are easily generalized to the conditional case, given the number of claims at the beginning of the interval. Applications to the case involving "two stages" are also considered. 
MELNIKOV, ALEXANDER V; TONG, SHUO. Quantile hedging on equity-linked life insurance contracts with transaction costs. 77-88. This paper analyzes the application of quantile hedging on equity-linked life insurance contracts in the presence of transaction costs. Following the time-based replication strategy, we present the explicit expressions for the present values of expected hedging errors and transaction costs. The results are derived by using the adjusted hedging volatility $\mathrm{s}$ proposed by Leland. Furthermore, the estimated values of expected hedging errors, transaction costs and total costs are obtained from a simulation approach for comparison. Finally, the costs of maturity guarantee for equity-linked life insurance contracts inclusive of transaction costs are discussed.

PENG, LIANG. Joint tail of ECOMOR and LCR reinsurance treaties. 116-120. Researchers in actuarial sciences have investigated the tail behavior of the LCR and ECOMOR reinsurance treaties separately for managing extreme risks in reinsurance business. In practice, a reinsurance company may possess these two treaties simultaneously. Therefore, investigating the joint tail behavior of these two treaties is practically useful in risk management. This paper derives the asymptotic limit of the joint tail of these two reinsurance treaties under the setup of Jiang and Tang (2008). [J. Jiang, Q. Tang, Reinsurance under the LCR and ECOMOR treaties with emphasis on light-tailed claims, Insurance Mathematics and Economics (2008) 43: 431-436]

PIGEON, MATHIEU; ANTONIO, KATRIEN; DENUIT, MICHEL. Individual loss reserving using paid-incurred data. 121-131. This paper develops a stochastic model for individual claims reserving using observed data on claim payments as well as incurred losses. We extend the approach of Pigeon et al. (2013) [M. Pigeon, K. Antonio, M. Denuit, Individual loss reserving with the multivariate skew normal framework, ASTIN Bulletin (2013) 43(3): 399-428], designed for payments only, towards the inclusion of incurred losses. We call the new technique the individual Paid and Incurred Chain (iPIC) reserving method. Analytic expressions are derived for the expected ultimate losses, given observed development patterns. The usefulness of this new model is illustrated with a portfolio of general liability insurance policies. For the case study developed in this paper, detailed comparisons with existing approaches reveal that iPIC method performs well and produces more accurate predictions.

ULM, ERIC R. Analytic solution for ratchet guaranteed minimum death benefit options under a variety of mortality laws. 14-23. We derive a number of analytic results for GMDB [guaranteed minimum death benefit] ratchet options. Closed form solutions are found for De Moivre's Law, Constant Force of Mortality, Constant Force of Mortality with an endowment age and constant force of mortality with a cutoff age. We find an infinite series solution for a general mortality laws and we derive the conditions under which this series terminates. We sum this series for at-themoney options under the realistic Makeham's Law of Mortality.

VALDEZ, EMILIANO A; VADIVELOO, JEYARAJ; DIAS, USHANI. Life insurance policy termination and survivorship. 138-149. There has been some work, e.g. Carriere (1998) [J. F. Carriere, Withdrawal benefits under a dependent double decrement model, ASTIN Bulletin (1998) 28: 49-57], Valdez (2000b) [E. A. Valdez, Life insurance mortality and lapsation, Journal of Risk Management and Insurance (2000) 5: 15-43], and Valdez (2001) [E. A. Valdez, Bivariate analysis of survivorship and persistency, Insurance Mathematics and Economics (2001) 29: 357-373], leading to the development of statistical models in understanding the mortality pattern of terminated policies. However, there is a scant literature on the empirical evidence of the true nature of the relationship between survivorship and persistency in life insurance. When a life insurance 
contract terminates due to voluntary non-payment of premiums, there is a possible hidden cost resulting from mortality antiselection. This refers to the tendency of policyholders who are generally healthy to select against the insurance company by voluntarily terminating their policies. In this article, we explore the empirical results of the survival pattern of terminated policies, using a follow-up study of the mortality of those policies that terminated from a portfolio of life insurance contracts. The data has been obtained from a major insurer which traced the mortality of their policies withdrawn, for purposes of understanding the mortality antiselection, by obtaining their dates of death from the Social Security Administration office. Using a representative sample of this follow-up data, we modeled the time until a policy lapses and its subsequent mortality pattern. We find some evidence of mortality selection and we consequentially examined the financial cost of policy termination.

YANG, HAIZHONG; LI, JINZHU. Asymptotic finite-time ruin probability for a bidimensional renewal risk model with constant interest force and dependent subexponential claims. 185-192. This paper considers a bidimensional renewal risk model with constant interest force and dependent subexponential claims. Under the assumption that the claim size vectors form a sequence of independent and identically distributed random vectors following a common bivariate Farlie-Gumbel-Morgenstern distribution, we derive for the finite-time ruin probability an explicit asymptotic formula.

ZHAO, LIN; WEI, JIAQIN; WANG, RONGMING. On dividend strategies with non-exponential discounting. 1-13. In this paper, we study the dividend maximization problem with a non-constant discount rate in a diffusion risk model. We assume that the dividends can only be paid at a bounded rate and restrict ourselves to Markov strategies. This is a time inconsistent control problem. The equilibrium [Hamilton-Jacobi-Bellman] HJB-equation is given and the verification theorem is proven for a general discount function. Considering a mixture of exponential discount functions and a pseudo-exponential discount function, we get equilibrium dividend strategies and the corresponding equilibrium value functions by solving the equilibrium HJB-equations.

ZOU, BIN; CADENILLAS, ABEL. Explicit solutions of optimal consumption, investment and insurance problems with regime switching. 159-167. We consider an investor who wants to select his optimal consumption, investment and insurance policies. Motivated by new insurance products, we allow not only the financial market but also the insurable loss to depend on the regime of the economy. The objective of the investor is to maximize his expected total discounted utility of consumption over an infinite time horizon. For the case of hyperbolic absolute risk aversion (HARA) utility functions, we obtain the first explicit solutions for simultaneous optimal consumption, investment, and insurance problems when there is regime switching. We determine that the optimal insurance contract is either no-insurance or deductible insurance, and calculate when it is optimal to buy insurance. The optimal policy depends strongly on the regime of the economy. Through an economic analysis, we calculate the advantage of buying insurance.

ZOU, BIN; CADENILLAS, ABEL. Optimal investment and risk control policies for an insurer: expected utility maximization. 57-67. Motivated by the AIG bailout case in the financial crisis of 2007-2008, we consider an insurer who wants to maximize his/her expected utility of terminal wealth by selecting optimal investment and risk control strategies. The insurer's risk process is modeled by a jump-diffusion process and is negatively correlated with the capital gains in the financial market. We obtain explicit solutions of optimal strategies for various utility functions. 
Insurance: Mathematics \& Economics

59,2014

AHMADI, SEYED SAEED; LI, JOHNNY SIU-HANG. Coherent mortality forecasting with generalized linear models: a modified time-transformation approach. 194-221. In this paper, we propose an alternative approach for forecasting mortality for multiple populations jointly. Our contribution is developed upon the generalized linear models introduced by Renshaw et al., (1996) [A. E. Renshaw, S. Haberman, P. Hatzoupoulos (1996), The modelling of recent mortality trends in United Kingdom male assured lives, British Actuarial Journal 2 (1996) 2: 449-477] and Sithole et al., (2000) [T. Z. Sithole, S. Haberman, R. J. Verrall (2000), An investigation into parametric models for mortality projections, with applications to immediate annuitants' and life office pensioners' data, Insurance Mathematics and Economics (2000) 27: 285-312], in which mortality forecasts are generated within the model structure, without the need of additional stochastic processes. To ensure that the resulting forecasts are coherent, a modified time-transformation is developed to stipulate the expected mortality differential between two populations to remain constant when the long-run equilibrium is attained. The model is then further extended to incorporate a structural change, an important property that is observed in the historical mortality data of many national populations. The proposed modeling methods are illustrated with data from two different pairs of populations: (1) Swedish and Danish males; (2) English and Welsh males and U.K. male insured lives.

AVRAM, FLORIN; PISTORIUS, MARTIJN. On matrix exponential approximations of ruin probabilities for the classic and Brownian perturbed Cramér-Lundberg processes. 57-64. Padé rational approximations are a very convenient approximation tool, due to the easiness of obtaining them, as solutions of linear systems. Not surprisingly, many matrix exponential approximations used in applied probability are particular cases of the first and second order "admissible Padé approximations" of a Laplace transform, where admissible stands for nonnegative in the case of a density, and for nonincreasing in the case of a ccdf (survival function). Our first contribution below is the observation that for Cramér-Lundberg processes and Brownian perturbed Cramér-Lundberg processes there are three distinct rational approximations of the Pollaczek-Khinchine transform, corresponding to approximating (a) the claims transform, (b) the stationary excess transform, and (c) the aggregate loss transform. A second contribution is providing three new always admissible second order approximations for the ruin probabilities of the Cramér-Lundberg process with Brownian perturbation, one of which reduces in the absence of perturbation to De Vylder's approximation. Our third contribution is a method for comparing the resulting approximations, based on the concept of largest weak-admissibility interval of the compounding/traffic intensity parameter $\mathrm{p}$.

BENKHELIFA, LAZHAR. Kernel-type estimator of the reinsurance premium for heavy-tailed loss distributions. 65-70. In this paper, we generalize the classical estimator of the reinsurance premium for heavy-tailed loss distributions with a kernel-type estimator. Since this estimator exhibits a bias, we propose its bias-reduced version by using a least-squares method. The asymptotic normality of the proposed estimators is established under suitable assumptions. A small simulation study is carried out to prove the performance of our approach.

BOHNERT, ALEXANDER; BORN, PATRICIA; GATZERT, NADINE. Dynamic bybrid products in life insurance: assessing the policyholders' viewpoint. 87-99. Dynamic hybrid life insurance products are intended to meet new consumer needs regarding stability in terms of guarantees as 
well as sufficient upside potential. In contrast to traditional participating or classical unit-linked life insurance products, the guarantee offered to the policyholders is achieved by a periodical rebalancing process between three funds: the policy reserves (i.e. the premium reserve stock, thus causing interaction effects with traditional participating life insurance contracts), a guarantee fund, and an equity fund. In this paper, we consider an insurer offering both, dynamic hybrid and traditional participating life insurance contracts and focus on the policyholders' perspective. The results show that higher guarantees do not necessarily imply a higher willingness-to-pay, but that in case of dynamic hybrid contracts, a minimum guarantee level should be offered in order to ensure that the willingness-to-pay exceeds the minimum premium the insurer has to charge when selling the contract. In addition, strong interaction effects can be found between the two products, which particularly impact the willingness-to-pay of the dynamic hybrids.

BRANDTNER, MARIO; KÜRSTEN, WOLFGANG. Solvency II, regulatory capital, and optimal reinsurance: How good are Conditional Value-at-Risk and spectral risk measures? 156-167. We study the problem of optimal reinsurance as a means of risk management in the regulatory framework of Solvency II under Conditional Value-at-Risk and, as its natural extension, spectral risk measures. First, we show that stop-loss reinsurance is optimal under both Conditional Valueat-Risk and spectral risk measures. Spectral risk measures thus constitute a more general class of suitable regulatory risk measures than specific Conditional Value-at-Risk. At the same time, the established type of stop-loss reinsurance can be maintained as the optimal risk management strategy that minimizes regulatory capital. Second, we derive the optimal deductibles for stop-loss reinsurance. We show that under Conditional Value-at-Risk, the optimal deductible tends towards restrictive and counter-intuitive corner solutions or "plunging", which is a serious objection against its use in regulatory risk management. By means of the broader class of spectral risk measures, we are able to overcome this shortcoming as optimal deductibles are now interior solutions. Especially, the recently discussed power spectral risk measures and the Wang risk measure are shown to avoid any plunging. They yield a one-to-one correspondence between the risk parameter and the optimal deductible and, thus, provide economically plausible risk management strategies.

CHIU, MEI CHOI; WONG, HOI YING. Mean-variance asset-liability management with asset correlation risk and insurance liabilities. 300-310. Consider an insurer who invests in the financial market where correlations among risky asset returns are randomly changing over time. The insurer who faces the risk of paying stochastic insurance claims needs to manage her asset and liability by taking into account of the correlation risk. This paper investigates the impact of correlation risk to the optimal asset-liability management (ALM) of an insurer. We employ the Wishart process to model the stochastic covariance matrix of risky asset returns. The insurer aims to minimize the variance of the terminal wealth given an expected terminal wealth subject to the risk of paying out random liabilities of compound Poisson process. This ALM problem then becomes a linear-quadratic stochastic optimal control problem with stochastic volatilities, stochastic correlations and jumps. The recognition of an affine form in the solution process enables us to derive the explicit closed-form solution to the optimal ALM portfolio policy, obtain the efficient frontier, and identify the condition that the solution is well behaved.

CHOI, MICHAEL C H; CHEUNG, ERIC C K. On the expected discounted dividends in the Cramér-Lundberg risk model with more frequent ruin monitoring than dividend decisions. 121-132. In this paper, we further extend the insurance risk model in Albrecher et al. (2011b), who proposed to only intervene in the compound Poisson risk process at the discrete time points $\{\mathrm{Lk}\} \mathrm{k}=08$ where the event of ruin is checked and dividend decisions are made. In practice, 
an insurance company typically balances its books (and monitors its solvency) more frequently than deciding on dividend payments. This motivates us to propose a generalization in which ruin is monitored at $\{\mathrm{Lk}\} \mathrm{k}=08$ whereas dividend decisions are only made at $\{\mathrm{Ljk}\} \mathrm{k}=08$ for some positive integer $\mathrm{j}$. Assuming that the intervals between the time points $\{\mathrm{Lk}\} \mathrm{k}=08$ are $\operatorname{Erlang}(\mathrm{n})$ distributed, the Erlangization technique (e.g. Asmussen et al., 2002) allows us to model the more realistic situation with the books balanced e.g. monthly and dividend decisions made e.g. quarterly or semi-annually. Under a dividend barrier strategy with the above randomized interventions, we derive the expected discounted dividends paid until ruin. Numerical examples about dividend maximization with respect to the barrier bb and/or the value of $\mathrm{j}$ are given.

DENUIT, MICHEL; LIU, LIQUN; MEYER, JACK. A separation theorem for the weak s-convex orders. 279-284. The present paper extends to higher degrees the well-known separation theorem decomposing a shift in the increasing convex order into a combination of a shift in the usual stochastic order followed by another shift in the convex order. An application in decision making under risk is provided to illustrate the interest of the result.

DJEHICHE, BOUALEM; LÖFDAHL, BJÖRN. Risk aggregation and stochastic claims reserving in disability insurance. 100-108. We consider a large, homogeneous portfolio of life or disability annuity policies. The policies are assumed to be independent conditional on an external stochastic process representing the economic-demographic environment. Using a conditional law of large numbers, we establish the connection between claims reserving and risk aggregation for large portfolios. Further, we derive a partial differential equation for moments of present values. Moreover, we show how statistical multi-factor intensity models can be approximated by onefactor models, which allows for solving the PDEs very efficiently. Finally, we give a numerical example where moments of present values of disability annuities are computed using finitedifference methods and Monte Carlo simulations.

ELING, MARTIN. Fitting asset returns to skewed distributions: are the skew-normal and skewstudent good models? 45-56. Vernic (2006), Bolancé et al. (2008), and Eling (2012) identify the skew-normal and skew-student as promising models for describing actuarial loss data. In this paper, we change the focus from the liability to the asset side and ask whether these distributions are also useful for analyzing the investment returns of insurance companies. To answer this question, we fit various parametric distributions to capital market data which has been used to describe the investment set of insurance companies. Our results show that the skew-student is an especially promising distribution for modeling asset returns such as those of stocks, bonds, money market instruments, and hedge funds. Combining the results of Vernic (2006), Bolancé et al. (2008), Eling (2012), and this paper, it appears that the skew-student is a promising actuarial tool since it describes both sides of the insurer's balance sheet reasonably well.

References: R. Vernic (2006), Multivariate skew-normal distributions with applications in insurance, Insurance Mathematics and Economics (2006) 38: 413-426; C. Bolancé, M. Guillen, E. Pelican, R. Vernic (2008), Skewed bivariate models and nonparametric estimation for the CTE risk measure, Insurance Mathematics and Economics (2008) 43(3): 386-393; M. Eling (2012), Fitting insurance claims to skewed distributions: are the skew-normal and skew-student good models? Insurance Mathematics and Economics (2012) 51: 239-248.

FENG, RUNHUAN; SHIMIZU, YASUTAKA. Potential measures for spectrally negative Markov additive processes with applications in ruin theory. 11-26. The Markov additive process (MAP) 
has become an increasingly popular modeling tool in the applied probability literature. In many applications, quantities of interest are represented as functionals of MAPs and potential measures, also known as resolvent measures, have played a key role in the representations of explicit solutions to these functionals. In this paper, closed-form solutions to potential measures for spectrally negative MAPs are found using a novel approach based on algebraic operations of matrix operators. This approach also provides a connection between results from fluctuation theoretic techniques and those from classical differential equation techniques. In the end, the paper presents a number of applications to ruin-related quantities as well as verification of known results concerning exit problems.

GBARI, SAMUEL; DENUIT, MICHEL. Efficient approximations for numbers of survivors in the Lee-Carter model. 71-77. In portfolios of life annuity contracts, the payments made by an annuity provider (an insurance company or a pension fund) are driven by the random number of survivors. This paper aims to provide accurate approximations for the present value of the payments made by the annuity provider. These approximations account not only for systematic longevity risk but also for the diversifiable fluctuations around the unknown life table. They provide the practitioner with a useful tool avoiding the problem of simulations within simulations in, for instance, Solvency 2 calculations, valid whatever the size of the portfolio.

GIJBELS, IRÈNE; HERRMANN, KLAUS. On the distribution of sums of random variables with copula-induced dependence. 27-44. We investigate distributional properties of the sum of $\mathrm{d}$ possibly unbounded random variables. The joint distribution of the random vector is formulated by means of an absolutely continuous copula, allowing for a variety of different dependence structures between the summands. The obtained expression for the distribution of the sum features a separation property into marginal and dependence structure contributions typical for copula approaches. Along the same lines we obtain the formulation of a conditional expectation closely related to the expected shortfall common in actuarial and financial literature. We further exploit the separation to introduce new numerical algorithms to compute the distribution and quantile function, as well as this conditional expectation. A comparison with the most common competitors shows that the discussed Path Integration algorithm is the most suitable method for computing these quantities. In our example, we apply the theory to compute Value-at-Risk forecasts for a trivariate portfolio of index returns.

HEILPERN, STANISLAW. Ruin measures for a compound Poisson risk model with dependence based on the Spearman copula and the exponential claim sizes. 251-257. This paper is devoted to an extension to the classical compound risk model. We relax the independence assumption of claim amounts and interclaim times. The dependent structure between these random variables is described by the Spearman copula. We study the Laplace transform of the discounted penalty function and we give the explicit expression of it for the exponential claim size.

HUANG, XIAOXIA; ZHAO, TIANYI. Mean-chance model for portfolio selection based on uncertain measure. 243-250. This paper discusses a portfolio selection problem in which security returns are given by experts' evaluations instead of historical data. A factor method for evaluating security returns based on experts' judgment is proposed and a mean-chance model for optimal portfolio selection is developed taking transaction costs and investors' preference on diversification and investment limitations on certain securities into account. The factor method of evaluation can make good use of experts' knowledge on the effects of economic environment and the companies' unique characteristics on security returns and incorporate the contemporary relationship of 
security returns in the portfolio. The use of chance of portfolio return failing to reach the threshold can help investors easily tell their tolerance toward risk and thus facilitate a decision making. To solve the proposed nonlinear programming problem, a genetic algorithm is provided. To illustrate the application of the proposed method, a numerical example is also presented.

\section{LEE, WING YAN; WILLMOT, GORDON E. On the moments of the time to ruin in dependent} Sparre Andersen models with emphasis on Coxian interclaim times. 1-10. The structural properties of the moments of the time to ruin are studied in dependent Sparre Andersen models. The moments of the time to ruin may be viewed as generalized versions of the Gerber-Shiu function. It is shown that structural properties of the Gerber-Shiu function hold also for the moments of the time to ruin. In particular, the moments continue to satisfy defective renewal equations. These properties are discussed in detail in the model of Willmot and Woo (2012) [G.E. Willmot, J.-K. Woo, On the analysis of a general class of dependent risk processes, Insurance Mathematics and Economics (2012) 51: 134-141], which has Coxian interclaim times and arbitrary time-dependent claim sizes. Structural quantities needed to determine the moments of the time to ruin are specified under this model. Numerical examples illustrating the methodology are presented.

MALINOVSKII, VSEVOLOD K; KOSOVA, KSENIA O. Simulation analysis of ruin capital in Sparre Andersen's model of risk. 184-193. Ruin capital is a function of premium rate set to render the probability of ruin within finite time equal to a given value. The analytical studies of this function in the classical Lundberg model of risk with exponential claim sizes done in Malinovskii (2014) [V. K. Malinovskii (2014), Improved asymptotic upper bounds on ruin capital in Lundberg model of risk, Insurance Mathematics and Economics (2014) 55: 301-309] have shown that the ruin capital's shape is surprisingly simple. This work presents the results of related simulation studies. They are focused on the question whether this shape remains similar in Sparre Andersen's model of risk.

PANTELOUS, ATHANASIOS A; YANG, LIN. Robust LMI stability, stabilization and [H8] control for premium pricing models with uncertainties into a stochastic discrete-time framework. 133-143. The premium pricing process and the reserve stability under uncertainty are very challenging issues in the insurance industry. In practice, a premium which is sufficient enough to cover the expected claims and to keep stable the derived reserves is always required. This paper proposes a premium pricing model for General (Non-Life) Insurance products, which implements a negative feedback mechanism for the known reserves with time-varying, bounded delays. The model is developed into a stochastic, discrete-time framework and norm-bounded parameter uncertainties have been also incorporated. Thus, the stability, the stabilization and the robust [H8] control for the reserve process are investigated using Linear Matrix Inequality (LMI) criteria. For the robust [H8] control, attention will be focused on the design of a state feedback controller such that the resulting closed-loop system is robustly stochastically stable with disturbance attenuation level $y>0$. Numerical examples and figures illustrate the main findings of the paper.

PENG, XINGCHUN; WEI, LINXIAO; HU, YIJUN. Optimal investment, consumption and proportional reinsurance for an insurer with option type payoff. 78-86. This paper is devoted to the study of optimization of investment, consumption and proportional reinsurance for an insurer with option type payoff at the terminal time under the criterion of exponential utility maximization. The surplus process of the insurer and the financial risky asset process are assumed to be diffusion processes driven by Brownian motions which are non-Markovian in general. Very general constraints are imposed on the investment and the proportional reinsurance processes. 
Based on the martingale optimization principle, we use BSDE and BMO martingale techniques to derive the optimal strategy and the optimal value function. Some interesting particular cases are studied in which the explicit expressions for the optimal strategy are given by using the Malliavin calculus.

PENG, XINGCHUN; CHEN, FENG; HU, YIJUN. Optimal investment, consumption and proportional reinsurance under model uncertainty. 222-234. This paper considers the optimal investment, consumption and proportional reinsurance strategies for an insurer under model uncertainty. The surplus process of the insurer before investment and consumption is assumed to be a general jump-diffusion process. The financial market consists of one risk-free asset and one risky asset whose price process is also a general jump-diffusion process. We transform the problem equivalently into a two-person zero-sum forward-backward stochastic differential game driven by two-dimensional Lévy noises. The maximum principles for a general form of this game are established to solve our problem. Some special interesting cases are studied by using Malliavin calculus so as to give explicit expressions of the optimal strategies.

PETERS, GARETH W; DONG, ALICE X D; KOHN, ROBERT. A copula based Bayesian approach for paid-incurred claims models for non-life insurance reserving. 258-278. Our article considers the class of recently developed stochastic models that combine claims payments and incurred losses information into a coherent reserving methodology. In particular, we develop a family of hierarchical Bayesian paid-incurred claims models, combining the claims reserving models of Hertig (1985) [J. Hertig, A statistical approach to the IBNR-reserves in marine insurance, Astin Bulletin (1985) 15 (2): 171-183] and Gogol (1993) [D. Gogol, Using expected loss ratios in reserving, Insurance Mathematics and Economics (1993) 12(3): 297-299]. In the process we extend the independent log-normal model of Merz and Wüthrich (2010) by incorporating different dependence structures using a Data-Augmented mixture Copula paid-incurred claims model. In this way the paper makes two main contributions: firstly we develop an extended class of model structures for the paid-incurred chain ladder models where we develop precisely the Bayesian formulation of such models; secondly we explain how to develop advanced Markov chain Monte Carlo sampling algorithms to make inference under these copula dependence PIC models accurately and efficiently, making such models accessible to practitioners to explore their suitability in practice. In this regard the focus of the paper should be considered in two parts, firstly development of Bayesian PIC models for general dependence structures with specialised properties relating to conjugacy and consistency of tail dependence across the development years and accident years and between Payment and incurred loss data are developed. The second main contribution is the development of techniques that allow general audiences to efficiently work with such Bayesian models to make inference. The focus of the paper is not so much to illustrate that the PIC paper is a good class of models for a particular data set, the suitability of such PIC type models is discussed in Merz and Wüthrich (2010) [M. Merz, M.V. Wüthrich, Paid-incurred chain claims reserving method, Insurance Mathematics and Economics (2010) 46(3): 568-579] and Happ and Wüthrich (2013) [M. Merz, M. V. Wüthrich, Estimation of tail factors in the paid-incurred chain reserving method, Variance (2013) 7(1): 61-73]. Instead we develop generalised model classes for the PIC family of Bayesian models and in addition provide advanced Monte Carlo methods for inference that practitioners may utilise with confidence in their efficiency and validity.

SPREEUW, JAAP. Archimedean copulas derived from utility functions. 235-242. The inverse of the (additive) generator of an Archimedean copula is a strictly decreasing and convex function, while utility functions (applying to risk averse decision makers) are nondecreasing and concave. 
This provides a basis for deriving an inverse generator of an Archimedean copula from a utility function. If we derive the inverse of the generator from the utility function, there is a link between the magnitude of measures of risk attitude (like the very common Arrow-Pratt coefficient of absolute risk aversion) and the strength of dependence featured by the corresponding Archimedean copula. Some new copula families are derived, and their properties are discussed. A numerical example about modeling dependence of coupled lives is included.

SUN, YING; WEI, LI. The finite-time ruin probability with heavy-tailed and dependent insurance and financial risks. 178-183. Consider a discrete-time insurance risk model in which the insurer makes both risk-free and risky investments. Assume that the one-period insurance and financial risks form a sequence of independent and identically distributed copies of a random pair $(\mathrm{X}, \mathrm{Y})$ with dependent components. When the product $\mathrm{XY}$ is heavy tailed, under a mild restriction on the dependence structure of $(\mathrm{X}, \mathrm{Y})$, we establish for the finite-time ruin probability an asymptotic formula, which coincides with the long-standing one in the literature. Various important special cases are presented, showing that our work generalizes and unifies some of recent ones.

\section{TAN, CHONG IT; LI, JACKIE; LI, JOHNNY SIU-HANG; BALASOORIYA, UDITHA. Parametric} mortality indexes: from index construction to hedging strategies. 285-299. In this paper, we investigate the construction of mortality indexes using the time-varying parameters in common stochastic mortality models. We first study how existing models can be adapted to satisfy the new-data-invariant property, a property that is required to ensure the resulting mortality indexes are tractable by market participants. Among the collection of adapted models, we find that the adapted Model M7 (the Cairns-Blake-Dowd model with cohort and quadratic age effects) is the most suitable model for constructing mortality indexes. One basis of this conclusion is that the adapted model M7 gives the best fitting and forecasting performance when applied to data over the age range of 40-90 for various populations. Another basis is that the three time-varying parameters in it are highly interpretable and rich in information content. Based on the three indexes created from this model, one can write a standardized mortality derivative called K-forward, which can be used to hedge longevity risk exposures. Another contribution of this paper is a method called key K-duration that permits one to calibrate a longevity hedge formed by K-forward contracts. Our numerical illustrations indicate that a K-forward hedge has a potential to outperform a q-forward hedge in terms of the number of hedging instruments required.

TANG, QIHE; YANG, FAN. Extreme value analysis of the Haezendonck-Goovaerts risk measure with a general Young function. 311-320. For a risk variable XX and a normalized Young function $\mathrm{f}(\cdot)$, the Haezendonck-Goovaerts risk measure for $\mathrm{X}$ at level $\mathrm{q}(0,1)$ is defined as $\mathrm{Hq}[\mathrm{X}]=\inf \mathrm{X}$ $\mathrm{R}(\mathrm{x}+\mathrm{h})$, where $\mathrm{h}$ solves the equation $\mathrm{E}[\mathrm{f}((\mathrm{X}-\mathrm{x})+/ \mathrm{h})]=1$-q if $\operatorname{Pr}(\mathrm{X}>\mathrm{x})>0$ or is 0 otherwise. In a recent work, we implemented an asymptotic analysis for $\mathrm{Hq}[\mathrm{X}]$ with a power Young function for the Fréchet, Weibull and Gumbel cases separately. A key point of the implementation was that hh can be explicitly solved for fixed $\mathrm{x}$ and $\mathrm{q}$, which gave rise to the possibility to express $\mathrm{Hq}[\mathrm{X}]$ in terms of $\mathrm{x}$ and $\mathrm{q}$. For a general Young function, however, this does not work anymore and the problem becomes a lot harder. In the present paper, we extend the asymptotic analysis for $\mathrm{Hq}[\mathrm{X}]$ to the case with a general Young function and we establish a unified approach for the three extreme value cases. In doing so, we overcome several technical difficulties mainly due to the intricate relationship between the working variables $\mathrm{x}, \mathrm{h}$ and $\mathrm{q}$.

YANG, JIANPING; ZHUANG, WEIWEI; HU, TAIZHONG. Lp-metric under the locationindependent risk ordering of random variables. 321-324. The Lp-metric $\mathrm{h}, \mathrm{p}(\mathrm{X})$ between the 
survival function $\mathrm{F}$ of a random variable $\mathrm{X}$ and its distortion $\mathrm{F}$ is a characteristic of the variability of $\mathrm{X}$. In this paper, it is shown that if a random variable $\mathrm{X}$ is larger than another random variable $\mathrm{Y}$ in the location-independent risk order or in the excess wealth order, then $h, p(X)=h, p(Y)$ whenever $\mathrm{p}(0,1]$ and the distortion function $\mathrm{h}$ is convex or concave. An alternative and simple proof of the corresponding known result in the literature for the dispersive order is given. Some applications are also presented.

ZHANG, HUIMING; LIU, YUNXIAO; LI, BO. Notes on discrete compound Poisson model with applications to risk theory. 325-336. Probability generating function (p.g.f.) is a powerful tool to study discrete compound Poisson (DCP) distribution. By applying inverse Fourier transform of $\mathrm{p}$. g.f., it is convenient to numerically calculate probability density and do parameter estimation. As an application to finance and insurance, we firstly show that in the generalized CreditRisk + model, the default loss of each debtor and the total default of all debtors are both approximately equal to a DCP distribution, and we give Le Cam's error bound between the total default and a DCP distribution. Next, we consider geometric Brownian motion with DCP jumps and derive its rth moment. We establish the surplus process of the difference of two DCP distributions, and numerically compute the tail probability. Furthermore, we define the discrete pseudo compound Poisson (DPCP) distribution and give the characterizations and examples of DPCP distribution, including the strictly decreasing discrete distribution and the zero-inflated discrete distribution with $\mathrm{P}(\mathrm{X}=0)>0.5$.

ZHANG, ZHIMIN; YANG, HAILIANG. Nonparametric estimation for the ruin probability in a Lévy risk model under low-frequency observation. 168-177. In this paper, we propose a nonparametric estimator for the ruin probability in a spectrally negative Lévy risk model based on low-frequency observation. The estimator is constructed via the Fourier transform of the ruin probability. The convergence rates of the estimator are studied for large sample size. Some simulation results are also given to show the performance of the proposed method when the sample size is finite.

ZHENG, YANTING; CUI, WEI. Optimal reinsurance with premium constraint under distortion risk measures. 109-120. Recently distortion risk measure has been an interesting tool for the insurer to reflect its attitude toward risk when forming the optimal reinsurance strategy. Under the distortion risk measure, this paper discusses the reinsurance design with unbinding premium constraint and the ceded loss function in a general feasible region which requiring the retained loss function to be increasing and left-continuous. Explicit solution of the optimal reinsurance strategy is obtained by introducing a premium-adjustment function. Our result has the form of layer reinsurance with the mixture of normal reinsurance strategies in each layer. Finally, to illustrate the applicability of our results, we derive the optimal reinsurance solutions with premium constraint under two special distortion risk measures - VaR and TVaR.

ZHU, YUNZHOU; CHI, YICHUN; WENG, CHENGGUO. Multivariate reinsurance designs for minimizing an insurer's capital requirement. 144-155. This paper investigates optimal reinsurance strategies for an insurer with multiple lines of business under the criterion of minimizing its total capital requirement calculated based on the multivariate lower-orthant Value-at-Risk. The reinsurance is purchased by the insurer for each line of business separately. The premium principles used to compute the reinsurance premiums are allowed to differ from one line of business to another, but they all satisfy three mild conditions: distribution invariance, risk loading and preserving the convex order, which are satisfied by many popular premium principles. Our results 
show that an optimal strategy for the insurer is to buy a two-layer reinsurance policy for each line of business, and it reduces to be a one-layer reinsurance contract for premium principles satisfying some additional mild conditions, which are met by the expected value principle, standard deviation principle and Wang's principle among many others. In the end of this paper, some numerical examples are presented to illustrate the effects of marginal distributions, risk dependence structure and reinsurance premium principles on the optimal layer reinsurance.

Insurance: Mathematics and Insurance abstracts.

Reproduced with the permission of Elsevier Science:

http://www.journals.elsevier.com/insurance-mathematics-and-economics

and published online through Science Direct:

http://www.sciencedirect.com/science/journal/01676687.

Subscription details available from: Elsevier Science, PO Box 311, 1000 AE Amsterdam, The Netherlands. E-mail: nlinfo-f@elsevier.nl

Journal of Risk and Insurance

81(1), 2014

ASMAT, DANIAL P; TENNYSON, SHARON. Does the threat of insurer liability for "bad faith" affect insurance settlements? 1-26. Economic reasoning predicts that policyholders in states that treat for insurer bad faith in settling claims as a tort should receive higher payments from insurers because of the greater potential damages insurers face in claims disputed in court. We test this hypothesis using data on automobile insurance claims for accidents occurring during 1972-1997, exploiting differences in states "laws and variation in timing of states" adoption of bad faith rules to identify the effects of tort liability. We find that the presence of tort liability for insurer bad faith increases settlement amounts and reduces the likelihood that a claim is underpaid.

BERNARD, CAROLE; VANDUFFEL, STEVEN. Financial bounds for insurance claims. 27-56. In this article, insurance claims are priced using an indifference pricing principle. We first revisit the traditional economic framework and then extend it to incorporate a financial (sub)market as a tool to invest and to (partially) hedge. In this context, we derive lower bounds for claims' prices, and these bounds correspond to the market prices of some explicitly known financial payoffs. In particular, we show that the discounted expected value is no longer valid as a classical lower bound for insurance prices in general: it has to be corrected by a covariance term that reflects the interaction between the insurance claim and the financial market. Examples that deal with equitylinked insurance contracts illustrate the article.

BRAUN, ALEXANDER; SCHMEISER, HATO; SIEGEL, CAROLINE. The impact of private equity on a life insurer's capital charges under Solvency II and the Swiss solvency test. 113-158. In this article, we conduct an in-depth analysis of the impact of private equity investments on the capital requirements faced by a representative life insurance company under Solvency II as well as the Swiss Solvency Test. Our discussion begins with an empirical performance measurement of the asset class over the period from 2001 to 2010, suggesting that limited partnership private equity funds may be suited for the purpose of portfolio enhancement. Subsequently, we review the market risk standard approaches set out by both regulatory regimes and outline a potential framework for an internal model. Based on an implementation of these solvency models, it is possible to demonstrate that private equity is overly penalized by the standard approaches. 
Hence, life insurers aiming to exploit the asset class's return potential may expect significantly lower capital charges when applying an economically sound internal model. Finally, we show that, from a regulatory capital perspective, it can even be less costly to increase the exposure to private rather than public equity.

CHANG, CAROLYN W; CHANG, JACK S K; WEN, MIN-MING. Optimum hurricane futures hedge in a warming environment: a risk-return jump-diffusion approach. 199-217. We develop an optimum risk-return hurricane hedge model in a doubly stochastic jump-diffusion economy. The model's concave risk-return trade-off dictates that a higher correlation between hurricane power and insurer's loss, a smaller variable hedging cost, and a larger market risk premium result in a less costly but more effective hedge. The resulting hedge ratio comprises of a positive diffusion, a positive jump, and a negative hedging cost component. Numerical results show that hedging hurricane jump risks is most crucial with jump volatility being the dominant factor, and the faster the warming the more pronounced the jump effects.

CHEUNG, K C; SUNG, K C J; YAM, S C P. Risk-minimizing reinsurance protection for multivariate risks. 219-236. In this article, we study the problem of optimal reinsurance policy for multivariate risks whose quantitative analysis in the realm of general law-invariant convex risk measures, to the best of our knowledge, is still absent in the literature. In reality, it is often difficult to determine the actual dependence structure of these risks. Instead of assuming any particular dependence structure, we propose the minimax optimal reinsurance decision formulation in which the worst case scenario is first identified, then we proceed to establish that the stop-loss reinsurances are optimal in the sense that they minimize a general law-invariant convex risk measure of the total retained risk. By using minimax theorem, explicit form of and sufficient condition for ordering the optimal deductibles are also obtained.

GATZERT, NADINE; WESKER, HANNAH. Mortality risk and its effect on shortfall and risk management in life insurance. 57-90. Mortality risk is a key risk factor for life insurance companies and can have a crucial impact on its risk situation. In general, mortality risk can be divided into different subcategories, among them unsystematic risk, adverse selection, and systematic risk. In addition, basis risk may arise in case of hedging, for example, longevity risk. The aim of this article is to holistically analyze the impact of these different types of mortality risk on the risk situation and the risk management of a life insurer. Toward this end, we extend previous models of adverse selection, empirically calibrate mortality rates, and study the interaction among the mortality risk components in the case of an insurer holding a portfolio of annuities and term life insurance contracts. For risk management, we examine natural hedging and mortality contingent bonds. Our results show that particularly adverse selection and basis risk can have crucial impact not only on the effectiveness of mortality contingent bonds, but also on the insurer's risk level, especially when a portfolio consists of several types of products.

HARPER, JOEL T; TREANOR, STEPHEN D. Pension conversion, termination, and wealth transfers. 177-198. This article explores the motivation to change their defined benefit pension plan by either terminating the plan and replacing it with a defined contribution plan or converting it to a cash balance plan. Using Form 5500 data as well as firm financial data, we find firms wishing to change their defined benefit plans are motivated by potential wealth transfer and tax implications. Firms terminating pension plans tend to have lower potential wealth transfers and lower taxes than firms converting to a cash balance plan, indicating a desire to modify the implicit contract instead of terminating the plan. 
KESTERNICH, IRIS; SCHUMACHER, HEINER. On the use of information in oligopolistic insurance markets. 159-175. We analyze the use of information in an oligopolistic insurance market with costly market entry. For intermediate values of entry costs, an equilibrium exists that is profit maximizing for incumbents and in which companies do not discriminate between high and low risks. The model therefore provides an explanation for the existence of "unused observables," that is, information that (1) insurance companies collect or could collect, (2) is correlated with risk, but (3) is not used to set premiums.

PAO, TSUNG-I; TZENG, LARRY Y; WANG, KILI C. Typhoons and opportunistic fraud: claim patterns of automobile theft insurance in Taiwan. 91-112. We present evidence to support the existence of opportunistic fraud in the automobile theft insurance market in Taiwan. After encountering a typhoon hit, the insured who purchase automobile theft insurance but do not purchase typhoon/flood insurance tend to have a significantly higher probability of filing a total theft claim than other insured. The above relationship exists mainly in places affected by typhoons. Such evidence does not exist in partial theft claim. These claim patterns of automobile theft insurance provide us with strong evidence that supports the existence of opportunistic fraud in the market.

Available for downloading from: http://www.openathens.net

Journal of Risk and Insurance

81(2), 2014

AKIN, S NURAY; PLATT, BRENNAN C. Insurance, consumer search, and equilibrium price distributions. 397-429. We examine a service market with two frictions: search is required to obtain price quotes, and insurance coverage for the service reduces household search effort. While fewer draws from a price distribution will directly raise a household's average price, the indirect effect of reduced search on price competition has a much greater impact, accounting for at least 89 percent of increased average expenditures. In this environment, a monopolist insurer will exacerbate the moral hazard by offering full insurance. A competitive insurance market typically results in partial insurance and significant price dispersion, yet a second-best contract would offer even less insurance coverage.

DUTTA, KABIR K; BABBEL, DAVID F. Scenario analysis in the measurement of operational risk capital: a change of measure approach. 303-334. At large financial institutions, operational risk is gaining the same importance as market and credit risk in the capital calculation. Although scenario analysis is an important tool for financial risk measurement, its use in the measurement of operational risk capital has been arbitrary and often inaccurate. We propose a method that combines scenario analysis with historical loss data. Using the Change of Measure approach, we evaluate the impact of each scenario on the total estimate of operational risk capital. The method can be used in stress-testing, what-if assessment for scenario analysis, and Loss Given Default estimates used in credit evaluations.

ELING, MARTIN; KIESENBAUER, DIETER. What policy features determine life insurance lapse? An analysis of the German market. 241-269. With the largest data set ever used for this purpose (covering more than 1 million contracts), we analyze the impact of product and policyholder characteristics on lapse in the life insurance market. The data are provided by a German life 
insurer and cover two periods of market turmoil that we incorporate into our proportional hazards and generalized linear models. The results show that product characteristics such as product type or contract age and policyholder characteristics such as age or gender are important drivers for lapse rates. Our findings improve the understanding of lapse drivers and might be used by insurance managers and regulators for value- and risk-based management.

FREES, EDWARD W; MEYERS, GLENN; CUMMINGS, A DAVID. Insurance ratemaking and a Gini index. 335-366. Welfare economics uses Lorenz curves to display skewed income distributions and Gini indices to summarize the skewness. This article extends the Lorenz curve and Gini index by ordering insurance risks; the ordering variable is a risk-based score relative to price, known as a relativity. The new relativity-based measures can cope with adverse selection and quantify potential profit. Specifically, we show that the Gini index is proportional to a correlation between the relativity and an out-of-sample profit (price in excess of loss). A detailed example using homeowners insurance demonstrates the utility of these new measures.

HUANG, H; MILEVSKY, MOSHE A; SALISBURY, T S. Valuation and hedging of the RuinContingent Life Annuity (RCLA) 367-395. We analyze an insurance instrument called a ruincontingent life annuity (RCLA), which is a stand-alone version of the option embedded inside a variable annuity (VA) but without the buyer having to transfer investments to the insurance company. The annuitant's payoff from an RCLA is a dollar of income per year for life, deferred until a certain wealth process hits zero. We derive the partial differential equation (PDE) satisfied by the RCLA value assuming no arbitrage, describe efficient numerical techniques, and provide estimates for RCLA values. The practical motivation is twofold. First, numerous insurance companies are now offering similar contingent deferred annuities (CDAs). Second, the U.S. Treasury and Department of Labor have encouraged DC plans to offer longevity insurance to participants and the RCLA might be the ideal product.

LIN, WEN-CHANG; LAI, YI-HSUN; POWERS, MICHAEL R. The relationship between regulatory pressure and insurer risk taking. 271-301. The article examines the risk-taking behavior of property-liability insurers in the presence of risk-based capital regulation. An option pricing model is developed to evaluate the expected regulatory cost and predict a nonlinear relationship between regulatory pressure and insurers' risk taking. We then conduct an empirical test using the simultaneous threshold regression. The result shows that there is a threshold effect of regulatory pressure on insurer risk taking. Poorly capitalized insurers seem to be aware of their proximity to regulatory interventions but do not fully respond to the impending regulatory pressure. This implies either regulatory interventions are not costly enough or they are too late, or both.

MÜLLER, HEINZ; SCHIESS, DAVID. Optimal design of the attribution of pension fund performance to employees. 431-468. The article analyzes risk sharing in a defined contribution pension fund in continuous time. According to a prespecified attribution scheme, the interest rate paid on the employees' accounts is a linear function of the fund's investment performance. For each attribution scheme, the pension fund maximizes the expected utility and the employees derive utility from their savings accounts. It turns out that all Pareto-optimal attribution schemes are characterized by the same optimal participation rate. We derive the total welfare gain that installs from replacing no participation with optimal participation. This welfare gain can be quantified and is substantial for reasonable parameter values.

Available for downloading from: http://www.openathens.net 
Journal of Risk and Insurance

81(3), 2014

BERRY-STÖLZLE, THOMAS R; NINI, GREGORY P; WENDE, SABINE. External financing in the life insurance industry: evidence from the financial crisis. 529-562. The financial crisis and subsequent recession generated sizable operating losses for life insurance companies, yet the consequences were far less significant than for other financial intermediaries. The ability to quickly generate new capital through external issuance and dividend reductions let life insurers maintain healthy levels of equity capital. We use this experience to examine the causes and consequences of external capital issuance by U.S. life insurance companies. We show that, in general, new capital is issued both to support the growth of new business and to replace capital depleted by operating losses. This second channel is particularly important during macroeconomic recessions. Notably, we do not find any evidence that insurers had difficulty generating new capital, unlike other financial service providers that required large amounts of public support. For life insurers, what changed following the financial crisis was the demand to raise external capital, but the supply of external capital appears to have remained constant.

CHEN, HUA; CUMMINS, J DAVID; VISWANATHAN, KRUPA S; WEISS, MARY A. Systemic risk and the interconnectedness between banks and insurers: an econometric analysis. 623-652. This article uses daily market value data on credit default swap spreads and intraday stock prices to measure systemic risk in the insurance sector. Using the systemic risk measure, we examine the interconnectedness between banks and insurers with Granger causality tests. Based on linear and nonlinear causality tests, we find evidence of significant bidirectional causality between insurers and banks. However, after correcting for conditional heteroskedasticity, the impact of banks on insurers is stronger and of longer duration than the impact of insurers on banks. Stress tests confirm that banks create significant systemic risk for insurers but not vice versa.

CUMMINS, J DAVID; DIONNE, GEORGES. Introduction: symposium on convergence, interconnectedness, and crises: insurance and banking. 473-476. A conference on Convergence, Interconnectedness, and Crises: Insurance and Banking was held at Temple University in Philadelphia from December 8 to 10, 2011. The conference was cosponsored by Temple University's Advanta Center for Research on Financial Institutions, SCOR Group, The Canada Research Chair in Risk Management, HEC Montreal, CIRPEE (Quebec, Canada), and The Journal of Risk and Insurance. Seventeen research papers and two keynote addresses were presented at the conference, and six papers from the conference are published in this symposium. The conference keynote addresses were delivered by Denis Kessler, Chairman and CEO of SCOR Group, and Andrew W. Lo, Harris \& Harris Group Professor of Finance, MIT Sloan School of Management.

CUMMINS, J DAVID; WEISS, MARY A. Systemic risk and the U.S. Insurance sector. 489-528. This article examines the potential for the U.S. insurance industry to cause systemic risk events that spill over to other segments of the economy. We examine primary indicators of systemic risk as well as contributing factors that exacerbate vulnerability to systemic events. Evaluation of systemic risk is based on a detailed financial analysis of the insurance industry, its role in the economy, and the interconnectedness of insurers. The primary conclusion is that the core activities of U.S. insurers do not pose systemic risk. However, life insurers are vulnerable to intrasector crises, and both life and property-casualty insurers are vulnerable to reinsurance crises. Noncore activities such as financial guarantees and derivatives trading may cause systemic risk, and interconnectedness 
among financial institutions has grown significantly in recent years. To reduce systemic risk from noncore activities, regulators need to continue efforts to strengthen mechanisms for insurance group supervision.

ELING, MARTIN; MAREK, SEBASTIAN D. Corporate governance and risk taking: evidence from the U.K. and German insurance markets. 653-682. We analyze the impact of factors related to corporate governance (i.e., compensation, monitoring, and ownership structure) on risk taking in the insurance industry. We measure asset, product, and financial risk in insurance companies and employ a structural equation model in which corporate governance is modeled as a latent factor. Based on this model, we present empirical evidence on the link between corporate governance and risk taking, considering insurers from two large European insurance markets. Higher levels of compensation, increased monitoring (more independent boards with more meetings), and more blockholders are associated with lower risk taking. Our empirical results provide justification for including factors related to corporate governance in insurance regulation.

GATZERT, NADINE; KOLB, ANDREAS. Risk measurement and management of operational risk in insurance companies from an enterprise perspective. 683-708. Operational risk can substantially impact an insurer's risk situation and is now increasingly in the focus of insurance companies, especially due to new European risk-based regulatory framework Solvency II. The aim of this article is to model and examine the effects of operational risk on fair premiums and solvency capital requirements under Solvency II. In particular, three different approaches of deriving solvency capital requirements are analyzed: the Solvency II standard model, a partial internal model, and a full internal model. This analysis is not only of relevance for Solvency II, but also regarding an insurer's Own Risk and Solvency Assessment (ORSA) that is not only planned in Solvency II, but also by the NAIC in the United States. The analysis emphasizes that diversification plays a central role and that operational risk measurement and management is highly relevant for insurers and should be integrated in an enterprise risk management framework.

KESSLER, DENIS. Why (re)insurance is not systemic. 477-488. The traditional model of (re) insurance lacks the elements that make a financial institution systemically important: risks are effectively pulverized; liabilities tend to be prefunded, which eliminates most of the leverage in the traditional sense; and active asset-liability management reduces most of the liquidity mismatch that traditionally propagates systemic risk. (Re)insurers that have stuck to this traditional business model have successfully weathered the crisis, even playing a stabilizing role. Unfortunately, this is not sufficiently recognized in the current IAIS/FSB1 debate on assessing systemic risk in the (re)insurance sector.

PARK, SOJUNG CAROL; XIE, XIAOYING. Reinsurance and systemic risk: the impact of reinsurer downgrading on property-casualty insurers. 587-622. This article analyzes the interconnectedness between reinsurers and U.S. property-casualty $(\mathrm{P} / \mathrm{C})$ insurers and presents the first detailed examination on the likely impact of major global reinsurer insolvency on the U.S. P/C insurance industry, in order to illustrate the potential systemic risk caused by the interconnectedness of the insurance sector through reinsurance. We find that the likelihood of a primary insurer's downgrade increases with its reinsurance default risk exposure from downgraded reinsurers. Counterparty primary insurers' stocks also react negatively to their reinsurers' downgrades. The negative effects also spill over to insurers that are not directly exposed to the credit risk of downgraded reinsurers. Despite the close interconnectedness, worst-case scenario analyses show that the likelihood of systemic risk caused by reinsurance transactions is relatively small for the U.S. P/C insurance industry. 
RÖSCH, DANIEL; SCHEULE, HARALD. Forecasting mortgage securitization risk under systematic risk and parameter uncertainty. 563-586. The global financial crisis exposed financial institutions to severe unexpected losses in relation to mortgage securitizations and derivatives. This article finds that risk models such as ratings are exposed to a large degree of systematic risk and parameter uncertainty. An out-of-sample forecasting exercise of the financial crisis shows that a simple approach addressing both issues is able to produce ranges for risk measures consistent with realized losses. This explains how financial markets were taken by surprise in relation to realized losses.

Journal of Risk and Insurance abstracts.

Reproduced with the permission of the American Risk and Insurance Association:

http://journalofriskandinsurance.smeal.psu.edu/about

Subscription details available from: the American Institute for CPCU, 720 Providence Road, Malvern, PA 19355, USA. E-mail: aria@cpcuiia.org

North American Actuarial Journal

18(3), 2014

ASANGA, SUJITH; ASIMIT, ALEXANDRU; BADESCU, ALEXANDRU; HABERMAN, STEVEN. Portfolio optimization under solvency constraints: a dynamical approach. 394-416. We develop portfolio optimization problems for a nonlife insurance company seeking to find the minimum capital required that simultaneously satisfies solvency and portfolio performance constraints. Motivated by standard insurance regulations, we consider solvency capital requirements based on three criteria: ruin probability, conditional Value-at-Risk, and expected policyholder deficit ratio. We propose a novel semiparametric formulation for each problem and explore the advantages of implementing this methodology over other potential approaches. When liabilities follow a Lognormal distribution, we provide sufficient conditions for convexity for each problem. Using different expected return on capital target levels, we construct efficient frontiers when portfolio assets are modeled with a special class of multivariate GARCH models. We find that the correlation between asset returns plays an important role in the behavior of the optimal capital required and the portfolio structure. The stability and out-of-sample performance of our optimal solutions are empirically tested with respect to both the solvency requirement and portfolio performance, through a double rolling window estimation exercise.

ERHARDT, ROBERT J; SMITH, RICHARD L. Weather derivative risk measures for extreme events. 379-393. We consider pricing weather derivatives for use as protection against weather extremes by using max-stable processes to estimate risk measures. These derivatives are not currently traded on any open markets, but their use could help some institutions manage weather risks from extreme events. The central challenge is to model the dependence of payments, which increases the risk of holding multiple weather derivatives. The method described utilizes results from spatial statistics and extreme value theory to first model extremes in the weather as a max-stable process, and then simulate payments for a general collection of weather derivatives. As the joint likelihood function for max-stable processes is unavailable, we use two approaches: The first is based on the composite likelihood, and the second is based on approximate Bayesian computing $(\mathrm{ABC})$. Both capture the spatial dependence of payments. To incorporate parameter uncertainty into the pricing model, we use bootstrapping with the composite likelihood 
approach, while the $\mathrm{ABC}$ method naturally incorporates parameter uncertainty. We show that the additional risk from the spatial dependence of payments can be quite substantial, and that the methods discussed can compute standard actuarial risk measures in both a frequentist and Bayesian setting.

HUA, LEI; XIA, MICHELLE. Assessing high-risk scenarios by full-range tail dependence copulas. 363-378. Copulas with a full-range tail dependence property can cover the widest range of positive dependence in the tail, so that a regression model can be built accounting for dynamic tail dependence patterns between variables. We propose a model that incorporates both regression on each marginal of bivariate response variables and regression on the dependence parameter for the response variables. An ACIG copula that possesses the full-range tail dependence property is implemented in the regression analysis. Comparisons between regression analysis based on ACIG and Gumbel copulas are conducted, showing that the ACIG copula is generally better than the Gumbel copula when there is intermediate upper tail dependence. A simulation study is conducted to illustrate that dynamic tail dependence structures between loss and ALAE can be captured by using the one-parameter ACIG copula. Finally, we apply the ACIG and Gumbel regression models for a dataset from the U.S. Medical Expenditure Panel Survey. The empirical analysis suggests that the regression model with the ACIG copula improves the assessment of high-risk scenarios, especially for aggregated dependent risks.

LIN, TZULING; TSAI, CARY CHI-LIANG. Applications of mortality durations and convexities in natural hedges. 417-442. Defining and deriving the mortality durations and convexities of the prices of life insurance and annuity products with respect to an instantaneously proportional change and an instantaneously parallel shift, respectively, in $\mu$ s (the forces of mortality), qs (the one-year death probabilities), ps (the one-year survival probabilities), $\ln (\mu) \mathrm{s},(\mathrm{q} / \mathrm{p}) \mathrm{s}$, and $\ln (\mathrm{q} / \mathrm{p}) \mathrm{s}$, this article applies 24 proposed duration/convexity matching strategies classified into seven groups to determine the weights of two products in an insurance portfolio. The hedging performances of some qualified matching strategies selected as representatives are evaluated by comparing their Value at Risk $(\mathrm{VaR})$ values and variance reduction ratios for a base scenario. We also test some specific scenarios for the population basis risk, model risk, volatility and jump risks, and interest rate risk to see the impacts on the matching strategies. Numerical examples show that some convexity matching strategies overall outperform the others in the VaR value and in the effectiveness of hedging both longevity and mortality risks for two kinds of insurance portfolios.

\section{North American Actuarial Journal}

$$
\text { 18(4), } 2014
$$

BELAYGORODAB, ANATOLIY; ZARDETTOA, ATILIO; LIU, YUANJIN. Bayesian modeling of shock lapse rates provides new evidence for emergency fund hypothesis. 501-514. This article considers the problem of estimating shock lapse rates in term life products. Four models are estimated using Bayesian Multiple-Block Gibbs sampling. Goodness-of-fit was compared using weighted average lapse rate fitted error. A simulated data setting was employed to validate the algorithm. Among the methodological contributions to the literature we introduce Bayesian estimation for the lapse rate parameters permitting the identification of parameter distributions as opposed to point estimates. Also we introduce a flexible panel data model accommodating both 
mixed effects and cross-effects between explanatory variables. The data are weighted in the likelihood function according to their relevance as measured by policy counts. Finally, we utilize a large proprietary dataset of U.S. postlevel premium period term policies that enables superior inference over the parameter estimates. Building on the above improvements and recent data covering the 2008 crisis, we find strong evidence in favor of the Emergency Fund Hypothesis as a driver of shock lapses.

BOYLE, PHELIM. Positive weights on the efficient frontier. 462-477. One of the fundamental insights of the Capital Asset Pricing Model is that the market portfolio is mean variance efficient. Since the market portfolio has positive weights on all assets, the conditions under which frontier portfolios have this property are of interest. This article derives a simple explicit solution for an efficient portfolio with positive weights. Assuming the covariance matrix is given, we obtain an expected return vector such that there is a compatible frontier portfolio. This portfolio is derived from the dominant eigenvector of the correlation matrix and provides a proxy for the market portfolio. Examples are provided to illustrate the basic idea.

FENG, RUNHUAN. A comparative study of risk measures for guaranteed minimum maturity benefits by a PDE method. 445-461. The stochastic modeling and determination of reserves and risk capitals for variable annuity guarantee products are relatively new developments in the insurance industry. The current market practice is largely based on Monte Carlo simulations, which have great engineering flexibility, but the demand for heavy computational power can be prohibitive in many cases. In this article we distinguish and compare two types of risk models to determine the commonly used risk measures for reserving and capital calculations. Using an example of the guaranteed minimum maturity benefit, we investigate alternative numerical methods that require less computational resources and yet achieve high accuracy and efficiency.

YANG, CHARLES C. Health care reform, efficiency of health insurers, and optimal health insurance markets. 478-500. This research examines the efficiency of the U.S. health insurers. It shows that more insurers are less efficient than in the previous sample year; however, the results suggest that the federal health care reform has no significant effect on the overall efficiency of all insurers as a whole, which is very low but does not change much over time. This research explores how to improve the efficiency of the health insurance market by proposing state, regional, and national efficiency-based goal-oriented market models and an efficiency duplicating system, and it discusses important implications to the health care compacts, the health insurance exchanges or marketplaces, and the national multistate programs. It also analyzes further moves for efficiency enhancement with regard to payment methods and the health care delivery system. One interesting finding is that the Medicaid program is very efficient because it provides support to the offering of Medicaid coverage and further expansion, which enhances the health welfare of society with fewer resources inputs from the perspective of efficiency. This research should provide important insights for state and federal governments, policy makers, regulators, the health insurance industry, and consumers.

North American Actuarial Journal abstracts

Reproduced with the permission of the Society of Actuaries

Subscription details available from: Society of Actuaries, 475 N. Martingale Road, Schaumburg, ILL 60173 USA

http://www.soa.org/news-and-publications/publications/journals/naaj/naaj-detail.aspx

It is now published online by Taylor \& Francis:: http://www.tandf.co.uk/journals/uAAJ 


\section{Scandinavian Actuarial Journal}

$$
5,2014
$$

BELKINA, TATIANA; HIPP, CHRISTIAN; LUO, SHANGZHEN; TAKSAR, MICHAEL. Optimal constrained investment in the Cramer-Lundberg model. 383-404. We consider an insurance company whose surplus is represented by the classical Cramer-Lundberg process. The company can invest its surplus in a risk-free asset and in a risky asset, governed by the Black-Scholes equation. There is a constraint that the insurance company can only invest in the risky asset at a limited leveraging level; more precisely, when purchasing, the ratio of the investment amount in the risky asset to the surplus level is no more than a; and when short-selling, the proportion of the proceeds from the short-selling to the surplus level is no more than $b$. The objective is to find an optimal investment policy that minimizes the probability of ruin. The minimal ruin probability as a function of the initial surplus is characterized by a classical solution to the corresponding Hamilton-Jacobi-Bellman (HJB) equation. We study the optimal control policy and its properties. The interrelation between the parameters of the model plays a crucial role in the qualitative behavior of the optimal policy. For example, for some ratios between a and b, quite unusual and at first ostensibly counterintuitive policies may appear, like short-selling a stock with a higher rate of return to earn lower interest, or borrowing at a higher rate to invest in a stock with lower rate of return. This is in sharp contrast with the unrestricted case, first studied in Hipp and Plum, or with the case of no short-selling and no borrowing studied in Azcue and Muler (2009) [Azcue, P. and Muler, M., Optimal investment strategy to minimize the ruin probability of an insurance company under borrowing constraints. Insurance Mathematics and Economics (2009) 44(1): 26-34].

CHI, YICHUN; MENG, HUI. Optimal reinsurance arrangements in the presence of two reinsurers. 424-438. In this paper, we investigate the optimal form of reinsurance from the perspective of an insurer when he decides to cede part of the loss to two reinsurers, where the first reinsurer calculates the premium by expected value principle while the premium principle adopted by the second reinsurer satisfies three axioms: distribution invariance, risk loading, and preserving stop-loss order. In order to exclude the moral hazard, a typical reinsurance treaty assumes that both the insurer and reinsurers are obligated to pay more for the larger loss. Under the criterion of minimizing value at risk $(\mathrm{VaR})$ or conditional value at risk $(\mathrm{CVaR})$ of the insurer's total risk exposure, we show that an optimal reinsurance policy is to cede two adjacent layers, where the upper layer is distributed to the first reinsurer. To further illustrate the applicability of our results, we derive explicitly the optimal layer reinsurance by assuming a generalized Wang's premium principle to the second reinsurer.

LANDRIAULT, DAVID; LEE, WING YAN; WILLMOT, GORDON E; WOO, JAE-KYUNG. A note on deficit analysis in dependency models involving Coxian claim amounts. 405-423. In this paper, we consider a fairly large class of dependent Sparre Andersen risk models where the claim sizes belong to the class of Coxian distributions. We analyze the Gerber-Shiu discounted penalty function when the penalty function depends on the deficit at ruin. We show that the system of equations needed to solve for this quantity is surprisingly simple. Various applications of this result are also considered.

OZKOK, ERENGUL; STREFTARIS, GEORGE; WATERS, HOWARD R; WILKIE, A DAVID. Modelling critical illness claim diagnosis rates I: methodology. 439-457. In a series of two papers, this paper and the one by Ozkok et al. (Modelling critical illness claim diagnosis rates II: results), we develop statistical models to be used as a framework for estimating, and graduating, Critical Illness (CI) insurance diagnosis rates. We use UK data for 1999-2005 supplied by the Continuous 
Mortality Investigation (CMI) to illustrate their use. In this paper, we set out the basic methodology. In particular, we set out some models, we describe the data available to us and we discuss the statistical distribution of estimators proposed for CI diagnosis inception rates. A feature of CI insurance is the delay, on average about 6 months but in some cases much longer, between the diagnosis of an illness and the settlement of the subsequent claim. Modelling this delay, the so-called Claim Delay Distribution, is a necessary first step in the estimation of the claim diagnosis rates and this is discussed in the present paper. In the subsequent paper, we derive and discuss diagnosis rates for CI claims from 'all causes' and also from specific causes.

OZKOK, ERENGUL; STREFTARIS, GEORGE; WATERS, HOWARD R; WILKIE, A DAVID. Modelling critical illness claim diagnosis rates II: results. 458-482. This is Paper II in a series of two papers. In Paper I we developed a methodology for estimating and graduating Critical Illness (CI) insurance diagnosis rates. In this paper we use data from the UK for 1999-2005 supplied by the Continuous Mortality Investigation (CMI) to illustrate our methodology by deriving and discussing all causes and cause specific critical illness diagnosis rates.

Scandinavian Actuarial Journal

6,2014

ARO, HELENA; PENNANEN, TEEMU. Stochastic modelling of mortality and financial markets. 483-509. The uncertain future development of mortality and financial markets affects every life insurer. In particular, the joint distribution of mortality and investment returns is crucial in determining capital requirements as well as in pricing and hedging of mortality-linked securities and other life insurance products. This paper proposes simple stochastic models that are well suited for numerical analysis of mortality-linked cash flows. The models are calibrated with a data set covering six countries and 56 years. Statistical analysis supports the known dependence of oldage mortality on GDP which, in turn, is connected to many sectors of financial markets. Our models allow for a simple quantitative description of such connections. Particular attention is paid to the long-term development of mortality rates, which is an important issue in life insurance.

FUCHS, SEBASTIAN. Consistent loss prediction for a portfolio and its subportfolios. 561-581. In the present paper, we consider a portfolio of risks consisting of two subportfolios, and we study the problem of whether or not the predictors based on the subportfolios are consistent with those based on the full portfolio. We study this aggregation problem for both the chain-ladder method and the additive method (or incremental loss ratio method). In the case of the chain-ladder method we extend results of Ajne [Ajne, B. Additivity of chain-ladder projections. ASTIN Bulletin (1994) 24: 311-318] and Klemmt [Klemmt, H. J. Separierung von Abwicklungsdreiecken nach Basisschäden und Großschäden. Blätter DGVFM (2005) 27: 49-58], using the duality of the chain-ladder method applied to incremental losses; we also give a short proof for this duality, which was first observed by Barnett, Zehnwirth \& Dubossarky [Barnett, G., Zehnwirth, B. and Dubossarsky, E. When can accident years be regarded as development years? Proceedings of the Casualty Actuarial Society (PCAS) (2005) 92: 239-256]. In the case of the additive method the aggregation problem has not been studied before and its solution is surprisingly simple.

VATAMIDOU, E; ADAN, I J B F; VLASIOU, M; ZWART, B. On the accuracy of phase-type approximations of heavy-tailed risk models. 510-534. Numerical evaluation of ruin probabilities 
in the classical risk model is an important problem. If claim sizes are heavy-tailed, then such evaluations are challenging. To overcome this, an attractive way is to approximate the claim sizes with a phase-type distribution. What is not clear though is how many phases are enough in order to achieve a specific accuracy in the approximation of the ruin probability. The goals of this paper are to investigate the number of phases required so that we can achieve a pre-specified accuracy for the ruin probability and to provide error bounds. Also, in the special case of a completely monotone claim size distribution we develop an algorithm to estimate the ruin probability by approximating the excess claim size distribution with a hyperexponential one. Finally, we compare our approximation with the heavy traffic and heavy tail approximations.

YENER, HALUK. Minimizing the lifetime ruin under borrowing and short-selling constraints. 535-560. In this paper, the optimal investment strategies for minimizing the probability of lifetime ruin under borrowing and short-selling constraints are found. The investment portfolio consists of multiple risky investments and a riskless investment. The investor withdraws money from the portfolio at a constant rate proportional to the portfolio value. In order to find the results, an auxiliary market is constructed, and the techniques of stochastic optimal control are used. Via this method, we show how the application of stochastic optimal control is possible for minimizing the probability of lifetime ruin problem defined under an auxiliary market.

\section{Scandinavian Actuarial Journal}

7,2014

ANTONIO, KATRIEN; PLAT, RICHARD. Micro-level stochastic loss reserving for general insurance. 649-669. The vast literature on stochastic loss reserving concentrates on data aggregated in run-off triangles. However, a triangle is a summary of an underlying data-set with the development of individual claims. We refer to this data-set as 'micro-level' data. Using the framework of Position Dependent Marked Poisson Processes) and statistical tools for recurrent events, a data-set is analyzed with liability claims from a European insurance company. We use detailed information of the time of occurrence of the claim, the delay between occurrence and reporting to the insurance company, the occurrences of payments and their sizes, and the final settlement. Our specifications are (semi)parametric and our approach is likelihood based. We calibrate our model to historical data and use it to project the future development of open claims. An out-of-sample prediction exercise shows that we obtain detailed and valuable reserve calculations. For the case study developed in this paper, the micro-level model outperforms the results obtained with traditional loss reserving methods for aggregate data.

GÓMEZ DÉNIZ, EMILIO; CALDERÍN-OJEDA, ENRIQUE. Unconditional distributions obtained from conditional specification models with applications in risk theory. 602-619. Bivariate distributions, specified in terms of their conditional distributions, provide a powerful tool to obtain flexible distributions. These distributions play an important role in specifying the conjugate prior in certain multi-parameter Bayesian settings. In this paper, the conditional specification technique is applied to look for more flexible distributions than the traditional ones used in the actuarial literature, as the Poisson, negative binomial and others. The new specification draws inferences about parameters of interest in problems appearing in actuarial statistics. Two unconditional (discrete) distributions obtained are studied and used in the collective risk model to compute the 
right-tail probability of the aggregate claim size distribution. Comparisons with the compound Poisson and compound negative binomial are made.

LIU, JINGZHEN; YIU, KA-FAI CEDRIC; SIU, TAK KUEN. Optimal investment of an insurer with regime-switching and risk constraint. 583-601. We investigate an optimal investment problem of an insurance company in the presence of risk constraint and regime-switching using a game theoretic approach. A dynamic risk constraint is considered where we constrain the uncertainty aversion to the 'true' model for financial risk at a given level. We describe the surplus of an insurance company using a general jump process, namely, a Markov-modulated random measure. The insurance company invests the surplus in a risky financial asset whose dynamics are modeled by a regime-switching geometric Brownian motion. To incorporate model uncertainty, we consider a robust approach, where a family of probability measures is cosidered and the insurance company maximizes the expected utility of terminal wealth in the 'worst-case' probability scenario. The optimal investment problem is then formulated as a constrained two-player, zero-sum, stochastic differential game between the insurance company and the market. Different from the other works in the literature, our technique is to transform the problem into a deterministic differential game first, in order to obtain the optimal strategy of the game problem explicitly.

SHIMIZU, YASUTAKA. Edgeworth type expansion of ruin probability under Lévy risk processes in the small loading asymptotics. 620-648. This paper presents an asymptotic expansion of the ultimate ruin probability under Lévy insurance risks as the loading factor tends to zero. The expansion formula is obtained via the Edgeworth type expansion for compound geometric distributions. We give higherorder expansion of the ruin probability, any order of which is available in explicit form, and discuss a certain type of validity of the expansion. We shall also give applications to evaluation of the VaR-type risk measure due to ruin, and the scale function of spectrally negative Lévy processes.

Scandinavian Actuarial Journal

8,2014

BRAZAUSKAS, VYTARAS; KLEEFELD, ANDREAS. Authors' reply to 'Letter to the Editor regarding folded models and the paper by Brazauskas and Kleefeld (2011)' 753-757. Reply by authors to Scollnik, D. (2012). Regarding folded models and the paper by Brazauskas and Kleefeld (2011), Scandinavian Actuarial Journal 2012, 1-4 about their paper: Brazauskas, V. \& Kleefeld, A. (2011). Folded and log-folded-t distributions as models for insurance loss data. Scandinavian Actuarial Journal (2011) 1: 59-79.

EISENBERG, JULIA. Asymptotic optimal investment under interest rate for a class of subexponential distributions. 671-689. We consider a classical risk model with the possibility of investment and positive interest rate for the riskless bond. The stock price movement is modelled as a geometric Brownian motion, the claim sizes are assumed to have a distribution belonging to a certain subclass of subexponential distributions. In this setting, we study the asymptotic behaviour of the optimal investment strategy under the ruin probability as a risk measure. This problem has been already considered before, but no results were obtained, for instance, for Weibull and Benktander-type-II distributions with certain parameters. We introduce a method which closes this gap.

JIN, TAO; REN, JIANDONG. Recursions and fast Fourier transforms for a new bivariate aggregate claims model. 729-752. Insurance companies typically face multiple sources (types) of claims. 
Therefore, modelling dependencies among different types of risks is extremely important for evaluating the aggregate claims of an insurer. In this paper, we first introduce a multivariate aggregate claims model, which allows dependencies among claim numbers as well as dependencies among claim sizes. For this proposed model, we derive recursive formulas for the joint probability functions of different types of claims. In addition, we extend the concept of exponential tilting to the multivariate fast Fourier transform and use it to compute the joint probability functions of the various types of claims. We provide numerical examples to compare the accuracy and efficiency of the two computation methods.

ROSENLUND, STIG. Inference in multiplicative pricing. 690-713. In multiplicative pricing of non-life insurance, we report a simulation study of mean square errors (MSEs) of point estimates by (1) the marginal totals method and (2) the Standard Generalized Linear Model (GLM) method of Poisson claim numbers and gamma distributed claim severities with constant coefficient of variation. MSEs per tariff cell are summed with insurance exposures as weights to give a total MSE. This is smallest for Standard GLM under the multiplicative assumption. But with moderate deviations from parameter multiplicativity, the study indicates that the marginal totals method is typically better in the MSE sense when there are many arguments and many claims, i.e. for mass consumer insurance. A method called MVW for confidence intervals, using only the compound Poisson model, is given for the marginal totals method. These confidence intervals are compared with the ones of Standard GLM and the Tweedie method for risk premiums in a simulation study and are found to be mostly the best. The study reports both cover probabilities, which should be close to 0.95 for $95 \%$ confidence intervals, and interval lengths, which should be small. The Tweedie method is found to be never better than Standard GLM.

ZADEH, AMIN HASSAN; JONES, BRUCE L; STANFORD, DAVID A. The use of phase-type models for disability insurance calculations. 714-728. This paper explores the use of phase-type models in actuarial calculations for disability insurance. We demonstrate that the changes in status of disability insureds can be appropriately captured by a phase-type model. Our model represents the aging process as the passage through a number of phases of decreasing vitality. When disabled, individuals additionally pass through several stages that represent duration of disability. Recovery and mortality rates from the earlier stages are greater than those in later stages. Using such a model, explicit and easily calculable expressions are obtained for relevant probabilities and actuarial present values. This facilitates the calculation of premiums and reserves.

\section{Scandinavian Actuarial Journal abstracts.}

Reproduced with the permission of Taylor \& Francis,

Access and subscription details available from: http://www.tandf.co.uk/journals/SACT

South African Actuarial Journal

14,2014

BERTOLIS, DINO ELIAS; HAYES, MARK. An investigation into South African general equity unit trust performance during different economic periods. 73-100. This paper investigates the performance of South African general equity unit trusts relative to the FTSE/JSE All Share Index during the period January 1994 to December 2012. The period under investigation was split into six further sub-periods each having a specific economic cycle: a downturn, average growth or 
robust growth. Unit trusts are shown to have underperformed in economic downturns and outperformed in periods of robust growth, while no conclusions can be made about unit trust performance during periods of average growth. Overall, unit trusts showed slight outperformance, but this was not found to be persistent.

DA SILVA, R; MILNER, K; KOLBE-ALEXANDER, TL; GREYLING, M; PATEL, D. The prevalence of chronic conditions associated with modifiable health risk factors in corporate employees in South Africa. 101-136. The Sunday Times Discovery Healthiest Company Index Survey collected a dataset of 13578 responses from corporate employees in 101 companies. This dataset has been used to assess the prevalence of self-reported modifiable health-risk factors and the association with chronic conditions. The analysis indicates that there is a greater likelihood of an individual reporting a chronic condition where their lifestyle risk factors are outside of the healthy range. This suggests that there are opportunities to manage the costs of health insurance, medical expenses and productivity losses by applying risk management tools aimed at addressing modifiable risk factors.

FLINT, E J; OCHSE, E R; POLAKOW, D A. Estimating long-term volatility parameters for marketconsistent models. 19-72. Contemporary actuarial and accounting practices (APN 110 in the South African context) require the use of market-consistent models for the valuation of embedded investment derivatives. These models have to be calibrated with accurate and up-to-date market data. Arguably, the most important variable in the valuation of embedded equity derivatives is implied volatility. However, accurate long-term volatility estimation is difficult because of a general lack of tradable, liquid medium- and long-term derivative instruments, be they exchangetraded or over the counter. In South Africa, given the relatively short-term nature of the local derivatives market, this is of particular concern. This paper attempts to address this concern by:

- providing a comprehensive, critical evaluation of the long-term volatility models most commonly used in practice, encompassing simple historical volatility estimation and econometric, deterministic and stochastic volatility models; and,

- introducing several fairly recent nonparametric alternative methods for estimating long-term volatility, namely break-even volatility and canonical option valuation.

The authors apply these various models and methodologies to South African market data, thus providing practical, long-term volatility estimates under each modelling framework whilst accounting for real-world difficulties and constraints. In so doing, they identify those models and methodologies they consider to be most suited to long-term volatility estimation and propose best estimation practices within each identified area. Thus, while application is restricted to the South African market, the general discussion, as well as the suggestion of best practice, in each of the evaluated modelling areas remains relevant for all long-term volatility estimation.

LOWTHER, MICHAEL W; MCMILLAN, W J. Authentic professional development: key to quality service delivery. 1-18. The Actuarial Society of South Africa ('Actuarial Society') requires its members to honour their professional promise to deliver specialist and up-to-date actuarial expertise that is ethical and subject to professional oversight. The purpose of this study is to investigate how the Actuarial Society can encourage its members to develop and maintain the capability to deliver this professional promise through continuing professional development ('CPD'). Current concepts of and approaches to professional development were identified from the literature and various professions' CPD requirements. Thereafter, the opinions of South African actuaries on the insights from the literature were sought by means of an online survey. Analysis of 
the literature indicates that CPD is most effective when it takes place through a development cycle of planning, action, results and reflection. Further, professional development is associated with competently completing tasks that are required in the workplace. Data from the survey supported these insights. It is concluded that the Actuarial Society's CPD requirements should be designed to encourage members to develop and maintain their capabilities, and it is therefore suggested that members be required to engage in work-based development cycles.

\section{South African Actuarial Journal abstracts.}

Reproduced with the permission of the Actuarial Society of South Africa.

Access to issues via: http://www.actuarialsociety.org.za/South-African-Actuarial-Journal-671.aspx

\section{Variance}

7(2), 2013

DORNHEIM, HARALD JOHANN; BRAZAUSKAS, VYTARAS. Case studies using credibility and corrected adaptively truncated likelihood methods. 168-192. Two recent papers by Dornheim and Brazauskas (2011a, 2011b) introduced a new likelihood-based approach for robust-efficient fitting of mixed linear models and showed that it possesses favorable large and small-sample properties which yield more accurate premiums when extreme outcomes are present in the data. In particular, they studied regression-type credibility models that can be embedded within the framework of mixed linear models for which heavy-tailed insurance data are approximately log-location-scale distributed. The new methods were called corrected adaptively truncated likelihood methods (or CATL, for short). In this paper, we build upon that work and further explore how CATL methods can be used for pricing risks. We extend the area of application of standard credibility ratemaking to several well-studied examples from property and casualty insurance, health care, and real estate fields. The process of outlier identification, the ensuing model inference, and related issues are thoroughly investigated on the featured data sets. Throughout the case studies, performance of CATL methods is compared to that of other robust regression credibility procedures. H Dornheim and V Brazauskas (2011a), Robust-efficient fitting of mixed linear models: Methodology and Theory, Journal of Statistical Planning and Inference 141 (4):1422-1435 H Dornheim and V Brazauskas (2011b), Robust-efficient credibility models with heavytailed claims: a mixed linear models perspective, Insurance: Mathematics and Economics, 48(1): 72-84.

ESCOTO, BENEDICT M. Bayesian claim severity with mixed distributions. 110-122. This paper presents a Bayesian technique for adjusting a mixed exponential severity distribution in response to partially-credible observed claim severities. It presents two applications: pricing excess of loss (XOL) reinsurance layers and computing increased limits factors (ILFs). The paper's Bayesian model uses a Dirichlet distribution over the mixed exponential's initial mixture weights. The posterior distribution, produced by conditionalizing on the observed claim severities, is computed using a Markov chain Monte Carlo method.

HAYNE, ROGER M. A flexible framework for stochastic reserving models. 123-151. Maximum likelihood estimators provide a powerful statistical tool. In this paper we directly deal with nonlinear reserving models, without the need to transform those models to make them tractable for linear or generalized linear methods. We also show how the same general approach can be easily adapted to provide estimates for a very wide range of reserving methods and models, making use of the same framework, and even much of the same computer code. We focus on the triangle of incremental average costs, and show how five common methods can be set in a stochastic framework. 
LAI, LI-HUA; WU, PEI-HSUAN. Tail-related risk measures of extreme value distribution: the case of Taiwan's rice damage due to typhoons in the non-crops insurance plan. 152-167. This paper adopts the extreme value and $\mathrm{VaR}$ approach to investigate the amount of rice damaged due to extreme events and analyzes the collective risk model as a feasible scheme for estimating annual aggregate losses. The results show that the annual frequency of rice damage caused by typhoons is shown to fit well the Poisson distribution with one parameter. The generalized Pareto distribution (GPD) with two parameters outperforms the log-normal fit with respect to the tail-related risk measures, e.g., VaR, ES, and EAS. GPD allows easy estimation of the high quantiles and the maximum probable loss from the data. The threshold value can be used as reference in decision making for setting grant-in-cash relief. We believe that, given different confidence intervals, these high-quantile measures can provide useful information in reviewing the applicable loss compensation regulations and for adjusting natural disaster relief budget plans or insurance pricing on the non-insurance plan.

WACEK, MICHAEL G. Discussion of paper published in Vol. 7, no. 1: 'Capital tranching: a RAROC approach to assessing reinsurance cost effectiveness' 101-109. In their short paper, the authors [Donald F Mango, John A Major, Avraham Adler, Claude Bunick] describe an elegant decision rule for evaluating the attractiveness of potential reinsurance transactions. In effect, they propose comparing the premium quoted by reinsurers for a particular reinsurance structure to the portion of its premiums the ceding company would need to allocate, given its cost of capital, to retain the risk. If the reinsurance premium is lower than the cedent's indicated capital cost premium, then the reinsurance is a buy. Otherwise, the risk should be retained. Before introducing their approach they set up a straw man in the form of what they refer to as the current "industry standard approach" or ISA, which they quickly and rightly demolish. Whether the ISA they describe is, in fact, in widespread use is debatable, but its defects for reinsurance decision-making and capital planning are serious, and the authors make a convincing case that their approach is superior. However, tantalizing as the authors' approach may be, the brevity of the paper, its reliance on a single example, and the lack of distinction in that example between the reinsurer's quoted premium and the ceding company capital cost premium make it difficult to see how a ceding company would apply it in practice. The aim of this discussion is to fill in key gaps in the paper in order to provide a clearer roadmap for the application of the proposed method.

Variance abstracts.

Reproduced with the permission of the Casualty Actuarial Society.

Access to Variance issues via: http://www.variancejournal.org/issues/

Subscription details available from: Casualty Actuarial Society, 4350N. Fairfax Drive, Suite 250, Arlington, VA 22203. USA. Tel.: +1 (703) 276-3100; Fax: +1 (703) (703) 276-3108, office@casact.org.

Apply per journal as applicable:

ASTIN Bulletin abstracts:

Reproduced with the permission of ASTIN (Actuarial Studies in Non-Life Insurance) of the International Actuarial Association and now published online by Cambridge Journals of Cambridge University Press:

http://journals.cambridge.org/action/displayJournal?jid=ASB

An archive of past Bulletins from 1958 to 2010 is available free through the IAA website: http://www.actuaries.org/index.cfm?lang=EN\&DSP=PUBLICATIONS\&ACT=ASTIN_BULLETIN 
Members who join ASTIN and AFIR receive and have access to ASTIN Bulletin. Members of the Institute and Faculty of Actuaries can join ASTIN and AFIR by contacting: membership@actuaries. org.uk

Subscription details available from: International Actuarial Association: https://www.actuaries.org/SECTIONS/SECTION_MEMBERSHIP_EN.cfm

Australian Journal of Actuarial Practice (successor to Australian Actuarial Journal) abstracts. Reproduced with the permission of the Institute of Actuaries of Australia. Access: http://www.actuaries.asn.au/knowledge-bank/journals

E-mail: actuaries@actuaries.asn.au

European Actuarial Journal abstracts.

Reproduced with the permission of Springer.

Subscription details available from: http://link.springer.com/contactus

http://link.springer.com/journal/13385

Geneva Papers on Risk and Insurance abstracts.

Reproduced with the permission of Palgrave MacMillan:

http://www.palgrave-journals.com/gpp/index.html

Subscription details available from: Palgrave Macmillan Subscription Department Tel: +44 (0)1256

357893, subscriptions@palgrave.com

Geneva Risk and Insurance Review abstracts.

Reproduced with the permission of Palgrave MacMillan:

http://www.palgrave-journals.com/grir/index.html

Subscription details available from: Palgrave Macmillan Subscription Department Tel: +44 (0)1256

357893, subscriptions@palgrave.com

Insurance: Mathematics and Insurance abstracts.

Reproduced with the permission of Elsevier Science:

http://www.journals.elsevier.com/insurance-mathematics-and-economics

and published online through Science Direct:

http://www.sciencedirect.com/science/journal/01676687.

Subscription details available from: Elsevier Science, PO Box 311, 1000 AE Amsterdam, The Netherlands. E-mail: nlinfo-f@elsevier.nl

Journal of Risk and Insurance abstracts.

Reproduced with the permission of the American Risk and Insurance Association:

http://journalofriskandinsurance.smeal.psu.edu/about

Subscription details available from: the American Institute for CPCU, 720 Providence Road,

Malvern, PA 19355, USA. E-mail: aria@cpcuiia.org

\section{North American Actuarial Journal abstracts}

Reproduced with the permission of the Society of Actuaries

Subscription details available from: Society of Actuaries, 475 N. Martingale Road, Schaumburg, ILL60173 USA

http://www.soa.org/news-and-publications/publications/journals/naaj/naaj-detail.aspx

It is now published online by Taylor \& Francis:: http://www.tandf.co.uk/journals/uAAJ 
Scandinavian Actuarial Journal abstracts.

Reproduced with the permission of Taylor \& Francis,

Access and subscription details available from: http://www.tandf.co.uk/journals/SACT

South African Actuarial Journal abstracts.

Reproduced with the permission of the Actuarial Society of South Africa.

Access to issues via: http://www.actuarialsociety.org.za/South-African-Actuarial-Journal-671.aspx

Variance abstracts.

Reproduced with the permission of the Casualty Actuarial Society.

Access to Variance issues via: http://www.variancejournal.org/issues/

Subscription details available from: Casualty Actuarial Society, 4350N. Fairfax Drive, Suite 250,

Arlington, VA 22203. USA. Tel.: +1 (703) 276-3100; Fax: +1 (703) (703) 276-3108, office@casact.org. 